\title{
Milton Friedman, the Demand for Money, and the ECB's Monetary Policy Strategy
}

\author{
Stephen G. Hall, P.A.V.B. Swamy, and George S. Tavlas
}

\begin{abstract}
The European Central Bank (ECB) assigns greater weight to the role of money in its monetary policy strategy than most, if not all, other major central banks. Nevertheless, reflecting the view that the demand for money became unstable in the early 2000s, some commentators have reported that the ECB has "downgraded" the role of money demand functions in its strategy. This paper explains the ECB's monetary policy strategy and shows the considerable influence of Milton Friedman's contributions on the formulation of that strategy. The paper also provides new evidence on the stability of euro area money demand. Following a conjecture made by Friedman (1956), the authors assign a role to uncertainty in the money demand function. They find that although uncertainty is nonstationary and subject to wide swings, it is nonetheless mean reverting and has substantial effects on the demand for money. (JEL C20, E41)
\end{abstract}

Federal Reserve Bank of St. Louis Review, May/June 2012, 94(3), pp. 153-85.

\section{INTRODUCTION}

$T^{1}$ he primary objective of the European Central Bank's (ECB's) monetary policy strategy is to maintain price stability in the medium term. ${ }^{1}$ In pursuing that objective, the ECB assigns more weight to the longer-term relationship between money growth and inflation than most, if not all, other major central banks. This emphasis reflects, in part, the ECB's views that (i) "inflation is ultimately a monetary phenomenon" and (ii) "price stability enhances the potential for economic growth" (ECB, 2011, pp. 55-56). Effectively, the emphasis reflects the notion that longer-term growth is determined by real factors-including an economy's resources, the growth of its population, and the technical skills of its labor force-and that the most monetary policy can do to help the economy reach its growth potential is deliver a stable price level (ECB, 2011, p. 56).

Stephen G. Hall is a professor of economics at Leicester University, visiting professor at Pretoria University, and a consultant to the Bank of Greece. P.A.V.B. Swamy is a former senior economist at the Board of Governors of the Federal Reserve System. George S. Tavlas is the director general of the Bank of Greece. The authors thank Eleni Argiri, Bill Gavin, Heather Gibson, Otmar Issing, Aggeliki Momtsia, Daphne Papadopoulou, Ifigeneia Skotida, Frank Smets, Mike Ulan, Hercules Vorides, and two referees for helpful comments. They also thank Christina Tsochatzi and Sophia Xanthopoulou for technical support and Thomas Vlassopoulos for providing the ECB's data on wealth. The views expressed are those of the authors and should not be interpreted as those of their respective institutions.

(c) 2012, The Federal Reserve Bank of St. Louis. The views expressed in this article are those of the author(s) and do not necessarily reflect the views of the Federal Reserve System, the Board of Governors, or the regional Federal Reserve Banks. Articles may be reprinted, reproduced, published, distributed, displayed, and transmitted in their entirety if copyright notice, author name(s), and full citation are included. Abstracts, synopses, and other derivative works may be made only with prior written permission of the Federal Reserve Bank of St. Louis. 


\section{Hall, Swamy, Tavlas}

In several important respects, the ECB's monetary policy strategy reflects the substantial influence of Milton Friedman's research during the 1950s and 1960s. $\stackrel{2}{ }$ One such respect concerns the stability of the demand for money, which helps underpin the idea that there exists a reliable, longer-term relationship between the growth in the money supply and inflation. Friedman (1959) found that demand for money in the United States was stable, a finding corroborated for the euro area in early work by the ECB staff (Calza, Gerdesmeier, and Levy, 2001). However, beginning around 2003, most euro area money demand functions began exhibiting instability, leading some commentators to infer that the role of money had been "downgraded" in the ECB's monetary policy strategy (see Section 2).

In this paper, we explain the key linkages between Friedman's work, including the relevance of a stable money demand function, and the strategy adopted by the ECB. We also provide new evidence on the stability of euro area money demand based on a framework that captures the effect of uncertainty on the demand for money, an idea first proposed by Friedman (1956).

The remainder of this paper is structured as follows. To set the stage, Section 1 provides an overview of Friedman's earlier research findings, which, as we show, underpinned his famous policy proposal for a constant money supply growth rate, first published in 1958. Section 2 describes the monetary policy strategy of the ECB, including the role of the demand for money in that strategy; this section also describes the influence of Friedman's work on the ECB's monetary policy strategy. We show that, although the finding in the mid-2000s by ECB economists that the demand for money in the euro area was no longer stable subsequently led to what the press reported as a "downgrading" of the role of money in the ECB's strategy, the role of monetary analysis in the ECB's strategy remains pivotal in assessing the outlook for future price developments. Section 3 turns to our analysis of euro area money demand and provides the basic theoretical framework we use to estimate money demand. Unlike previous empirical studies of money demand, we include a measure of economic sentiment to capture the effect of uncertainty on money demand. As noted by Friedman (1956) and reflected in the capital asset pricing model, during times of declining confidence (or increasing uncertainty), any asset should yield an increased rate of return to compensate for the increased risk. If the rate of return does not rise to mirror the increase in uncertainty, there will be a flight to liquid assets, such as money. This confidence effect can be extremely important during times of crises. The recent crisis in the euro area provides an apt setting to test that hypothesis. Section 4 describes the two empirical methodologies we use to estimate euro area money demand: (i) the workhorse vector error correction (VEC) approach and (ii) a generalized cointegration approach, which is estimated on the basis of a time-varying coefficient (TVC) technique. Section 5 presents the empirical findings. To anticipate briefly, both empirical methodologies suggest that, accounting for uncertainty, the long-run demand for money in the euro area has been stable. We find that although uncertainty is nonstationary and subject to wide swings, it is nonetheless mean reverting and has substantial effects on the demand for money. Section 6 offers our conclusions with the implications for the ECB's monetary policy strategy.

\section{HOW THE CONSTANT MONEY SUPPLY RULE WAS FORMED}

Friedman joined the University of Chicago faculty in 1946 and remained at that institution until his retirement from teaching (and his move to the Hoover Institution) in 1977. He began 
collaboration with Anna Schwartz on U.S. monetary history in 1948, around the same time that he began conducting a Workshop in Money and Banking at the University of Chicago. $\frac{3}{-}$ He first proposed the constant money growth rule in a 1958 paper, "The Supply of Money and Changes in Prices and Output," submitted to the Congressional Joint Economic Committee. 4 Friedman (1958, p. 174) stated that his aim was to summarize "the preliminary results" of his work with Schwartz and the series of studies conducted in the Chicago Workshop in Money and Banking under his direction. A main implication of those results is the need to distinguish between longrun, or secular, empirical relationships and short-run, or cyclical, relationships; the former tend to show considerable stability, whereas the latter are subject to large uncertainty. The money growth rate rule was formulated on the basis of long-run relationships. The following discussion draws on three Friedman studies: (i) the 1958 study presented to the Joint Economic Committee; (ii) a 1959 paper, "The Demand for Money: Some Theoretical and Empirical Results," published in the Journal of Political Economy; and (iii) a 1960 book, A Program for Monetary Stability, which was based on a series of Friedman's lectures at Fordham University in 1959. The discussion focuses on those empirical findings that underpinned the money growth rule. $\frac{5}{}$

\subsection{The Long Run}

Money and Prices. The historical evidence suggests a high correlation between changes in the stock of money per unit of output and changes in prices in the same direction. Friedman noted that this correlation "tells nothing about direction of influence" (1958, p. 173). However, the variety of monetary arrangements-for example, the gold standard, flexible exchange rates, regimes with and without a central bank, changes in the structure of the Federal Reserve System and commercial banking, shifts in leadership of the Fed-over which this regularity has been observed "supports strongly... [the view] that substantial changes in the stock of money are both a necessary and sufficient condition for substantial changes in the general level of prices" (1958, p. 173).

Definition of Money. How should the money supply be defined? Friedman argued that "there is a continuum of assets possessing in various degrees the qualities we attribute to the ideal construct of 'money' and hence there is no unique way to draw a line separating 'money' from 'near-moneys"' (1960, p. 90). The "most useful concept" is that corresponding to currency held by the public plus adjusted demand deposits plus time deposits in commercial banks ${ }^{6}$ "because it seems more closely related empirically to income and other economic magnitudes than other concepts" (1960, pp. 90-91, emphasis added).

Output and Prices. Historical evidence indicates that there is no clear-cut relation between price changes and output changes. The "only conclusion" that can be drawn from this evidence is that "either rising prices or falling prices are consistent with rapid economic growth, provided that the price changes are fairly steady, moderate in size, and reasonably predictable" (Friedman, 1959 , p. 184). The underpinnings to economic growth are to be found in such factors as "available resources, the industrial organization of a society, the growth of knowledge and technical skills, the growth of population, the accumulation of capital and so on" (1959, p. 182). On average, over a period of 90 years (from 1867 to 1957), the average annual growth in output has been "something over three percent" (1960, p. 91).

Income Velocity. Friedman (1959) reported empirical findings of his work with Schwartz on secular changes in the real money stock per capita and secular changes in real income per 


\section{Hall, Swamy, Tavlas}

capita over the period 1870 to 1954 for 20 reference cycles measured from trough to trough. The observations consisted of average values of the variables concerned over the complete cycle. The findings showed that "secular changes in the real stock of money per capita are highly correlated with secular changes in real income per capita" (1959, p. 113). The correlation coefficient between the logarithm of the real stock of money per capita and the logarithm of real income per capita was found to be 0.99 and the computed elasticity was 1.80 (1959, p. 113). Hence, a 1 percent increase in income per capita was, on average, associated with a 0.80 percent decrease in income velocity. Friedman noted that the high correlation could be a reflection of trends in the data such that the results might "not justify much confidence that the statistical regression is a valid estimate of a demand relation rather than the result of an accidental difference in trends" (1959, p. 113). He noted, however, that "additional evidence from other sources leads us to believe that it can be so regarded" (1959, p. 113).

In the same paper (1959), Friedman's (log-linear) estimation of the demand for money corroborated the above findings. The specification of the money demand function consisted of the following elements: (i) the dependent variable was nominal cash balances (i.e., M2) per capita; (ii) the explanatory variables were measures of permanent income, permanent prices, and population; and (iii) the estimation period was 1870 to 1954 . Using average values of the variables over the cycle (measured from trough to trough),, Friedman (1959, pp. 126-27) estimated an income elasticity of nominal cash balances of 1.810 , which implied a velocity elasticity of -0.810 . He then used these parameters to compute annual estimates of velocity, which he compared with the actual figures. He found that the estimates accounted for "the bulk of the fluctuations of measured velocity" (1959, p. 130). "These results," he argued, "give strong support to the view that cyclical movements in velocity largely reflect movements along a stable demand curve for money" (1959, p. 130)..

\subsection{The Short Run}

The foregoing secular empirical relationships, Friedman found, do not hold tightly within the business cycle. In his paper for the Joint Economic Committee, Friedman reported that his research with Schwartz revealed that although there is a close link between monetary changes and price changes within the business cycle, "the direction of influence between the money stock and income and prices is less clear-cut and more complex for the business cycle than for the longer movements" (1958, p. 179). This circumstance, he argued, reflected three factors.

First, "the character of our monetary and banking system means that an expansion of income contributes to expansion in the money stock, partly through inducing banks to trim more closely their cash reserve position, partly through a tendency for currency in public hands to decline relative to deposits" (Friedman, 1958, p. 179). Thus, Friedman argued that during the business cycle, changes in the money supply are "a consequence as well as an independent cause of changes in income and prices” (1958, p. 179). Moreover, once a cyclical expansion or contraction is started the process is self-generating: "[O]nce they [changes in money, income, and prices] occur, they will in their turn produce further effects on income and prices" (1958, p. 179).

Second, consideration of the timing of changes in the money supply, income, and prices complicates the relationship among these variables, making it more difficult to infer an independent influence of monetary change within the cycle than for secular movements. Within the 
cycle, the relationship among these variables is subject to lags. His work with Schwartz provided quantitative estimates of the lags. The lags were found to be long-on average, the rate of change in the money supply reached its peak nearly 16 months before the peak in economic activity and reached its trough over 12 months before the trough in economic activity; the lag lengths also varied considerably from cycle to cycle (1958, p. 180; 1960, p. 88).

Third, and related to the previous factor, within the cycle real shocks to velocity have been a source of economic fluctuations (Friedman, 1958, p. 89). Discretionary monetary policy in reaction to such shocks serves to amplify the effects of these real disturbances on the economy. 9 In the absence of the reaction of monetary policy, the shocks would merely constitute "the myriad of factors making for minor fluctuations in economic activity" (1959, p. 144).

\subsection{The Policy Rule}

The above evidence underpinned Friedman's proposal that the money supply-defined as currency held by the public plus demand and time deposits in commercial banks (M2)-should increase by between 3 and 5 percent per year (Friedman, 1958, p. 184). The secular empirical relationships informed both the particular concept of money used and the numerical margins (i.e., 3 to 5 percent) of the growth range. Specifically, Friedman chose M2 because of its close empirical relationship to "income and other economic magnitudes" (1960, p. 91). 10 During the period 1867 to 1957, output growth, Friedman noted, had averaged about 3 percent per year, whereas velocity had exhibited a secular decrease of about 1 percent per year (1958, pp. 184-85; 1960, pp. 90-91). Thus, "to judge from this evidence, a rate of increase [of M2] of 3 to 5 percent per year might be expected to correspond with a roughly stable price level for this particular concept of money" (1960, p. 91).

Why conduct policy in terms of a rule instead of using discretion? In A Program for Monetary Stability, Friedman argued that a rule would be easy to understand and would eliminate "the danger of instability and uncertainty of policy" (1960, p. 86). He also argued that discretion absolves the policymakers of any criteria from which to judge their performance and leaves them vulnerable to political pressures (1960, p. 85). Finally, relying on the evidence of his work with Schwartz on short-term relationships, Friedman argued that, in the past, discretion had led to "continual and unpredictable shifts in policy and in the content of policy as the persons and attitudes dominating the authorities had changed" (1960, p. 85). A money growth rule, he believed, would have avoided the "excessive" mistakes of the past, including the collapse of money from 1929 to 1933, the discount rate increases of 1931, and the resulting depression (1960, p. 93). It would not rule out mild cyclical fluctuations, but it "would almost certainly rule out... rapid and sizeable fluctuations" (1960, p. 92). Friedman argued that the implementation of his money supply proposal has a further advantage: "[I]t would largely separate the monetary problem from the fiscal [problem]" (1960, p. 90). As discussed in the following section, Friedman's empirical findings with regard to both the long run and the short run helped shape the monetary strategy adopted by the ECB.

\subsection{The Phillips Curve and Expectations}

In addition to the above contributions made during the 1950s, another contribution by Friedman that would later have an impact on the ECB's monetary policy strategy was his rebuttal 


\section{Hall, Swamy, Tavlas}

of the traditional Phillips curve notion that there exists a permanent trade-off between the unemployment rate and the inflation rate. Along with Phelps (1968), Friedman (1968) demonstrated that the steady-state unemployment rate is not related to the steady-state inflation rate when the Phillips relationship is augmented by a variable representing the expected inflation rate-that is, labor negotiates on the basis of real, and not nominal, wages. Consequently, in the long run there can be only varying levels of the inflation rate-which, in turn, depend on the steady-state change in the money supply-with the same "natural" level of the unemployment rate. This insight was a formalization of Friedman's earlier (1950s) research showing that, in the long run, the monetary authorities can control only nominal values.

\section{THE ECB'S MONETARY POLICY STRATEGY}

As we noted in our introduction, the primary objective of the ECB's monetary policy is to achieve price stability in the medium term. 11 The Governing Council 12 of the ECB defines price stability as a year-on-year increase in the Harmonised Index of Consumer Prices (HICP) for the euro area of "below, but close to, 2 percent in the medium term" (ECB, 2011, p. 64). $\frac{13}{}$ The ECB sees several advantages in this particular formulation of its policy objective (Issing and Tristani, 2005, pp. 62-64; Carboni, Hofmann, and Zampoli, 2010; ECB, 2011, pp. 64-67). First, it is easy to understand, thereby contributing to the transparency of monetary policy. Second, it provides a yardstick with which to gauge the ECB's performance, thus providing accountability. Third, it provides an anchor for the formation of price expectations, under the assumption that expectations of inflation are a key determinant of actual inflation. Fourth, it provides a "safety margin" between the price stability objective (below, but close to, 2 percent) and zero inflation. Fifth, it helps deal with the issue of the possible presence of upward measurement error bias in the HICP, whereby the measured inflation rate may overestimate the "true" inflation rate because the former does not adequately reflect such factors as improvements in the quality of products. Sixth, because the definition does not specify a precise numerical objective, it provides some allowance for inflation differentials within a monetary union composed of heterogeneous countries.

\subsection{The Influence of Friedman}

Many of the foregoing advantages attributed by the ECB to the formulation of its policy objective have been influenced, explicitly or implicitly, by Friedman's work. $\underline{14}$ In this regard, consider the following influences (see the boxed insert on the next page):

- As noted above, the main objective of Friedman's money growth rule was to eliminate policy uncertainty. In explaining the rationale for the ECB's monetary policy strategy, Issing et al. stated: "[T]he structure of any monetary policy strategy must reflect the extent and the nature of the uncertainties faced by the central bank. Different prevailing sources of uncertainty will normally require different strategies, i.e. differences in the way information is processed in order to attain policy decisions. The ECB strategy, in particular, was tailored having specifically in mind the uncertainties existing in the conduct of the single monetary policy" (ECB, 2001, p. 99).

- Friedman expressed the view that an advantage of his constant money growth proposal was that it would be easy to understand, while holding policymakers accountable for 


\section{A Comparison of Friedman's Principles and ECB Policies}

\section{Friedman}

ECB

Policy objective: Price stability (not precisely defined).

Policy implementation: Increase the money supply (M2) by 3 to 5 percent annually.

An advantage of a money growth rule is that it is easy to understand.

An objective of a money growth rule is to eliminate policy uncertainty.

Long-run money demand is stable.

Real money demand is subject to autonomous shocks.

The central bank can control nominal magnitudesbut not real magnitudes-in the long run.

Monetary policy actions have long and variable lags.

Countercyclical policy is often destabilizing.

It is important to maintain a clear separation of monetary policy from fiscal policy.

A money growth rule would be a means of providing the central bank with independence.

Expectations-augmented Phillips curve: Price expectations are a key determinant of present inflation.
Policy objective: Price stability, defined as an inflation rate below, but close to, 2 percent in the medium term.

Policy implementation: "Two pillars"-_economic analysis" and "monetary analysis" - are used to assess the risks to price stability.

At inception of the ECB, a 4.5 percent reference value for money supply (M3) growth was set. The reference value was a norm, not an objective.

Policy objective (price stability in the medium term) is transparent and easy to understand.

Policy is tailored to reduce uncertainties related to the current state of the economy, the behavior of economic agents (parameter uncertainty), and the nature of the true economic model (model uncertainty).

Money demand was found to be stable through early 2000 s and unstable thereafter. The role of a reference value was, therefore, diminished.

Medium-term orientation allows policy to respond flexibly to temporary shocks.

Policy focuses on controlling the price level, a nominal magnitude.

Medium-term orientation aims to account for long and variable lags of monetary policy actions.

Medium-term orientation is an acknowledgment that countercyclical policy can increase instability.

Article 123 of the Treaty on the Functioning of the European Union (the Treaty) prohibits the monetary financing of fiscal actions.

Article 130 of the Treaty provides the ECB independence from political influence.

The definition of price stability provides an anchor for the formation of price expectations, under the presumption that price expectations are a key determinant of present inflation. 


\section{Hall, Swamy, Tavlas}

their actions (Friedman, 1960, pp. 85-90). The ECB's medium-term price stability objective is based, in part, on the criteria of transparency and accountability.

- The ECB's emphasis on the price level-a nominal magnitude_-"echoes recommendations put forward by Milton Friedman" that the monetary authority can control nominal, but not real, variables (Issing and Tristani, 2005, p. 10).

- The medium-term orientation is an explicit acknowledgment "that Milton Friedman's assertion about the long and variable lags of the [monetary] transmission mechanism remains valid" (Issing and Tristani, 2005, p. 29). It is also an acknowledgment of "the possibility emphasized by Friedman...that counter-cyclical policy may actually increase instability in economic activity" (Issing, Gaspar, and Vestin, 2005, p. 120).

- As mentioned above, Friedman wrote that it was important to maintain a clear separation of monetary policy from fiscal policy. Article 123 of the Treaty on the Functioning of the European Union (the Treaty), which is the legal basis of the ECB's setting of monetary policy, prohibits the monetary financing of fiscal actions, thereby drawing a clear line of separation between monetary policy and fiscal policy (ECB, 2011, p. 15).

- One objective of Friedman's money growth rule was to provide independence for the monetary authorities (Friedman, 1960, p. 93). Article 130 of the Treaty lays down an "institutional framework for the [ECB's] monetary policy [under which the] central bank...is independent from political influence" (ECB, 2011, p. 14). $\underline{15}$

- The idea that expectations of inflation are a key determinant of present inflation is directly related to Friedman's (1968) augmentation of the Phillips curve, under which the actual inflation rate was shown to be dependent on a variable representing the expected inflation rate.

\subsection{The Two-Pillar Approach}

In pursuing its objective of price stability, the ECB's Governing Council regularly assesses risks to price stability on the basis of two organizing perspectives-known as the "two pillars" (see the boxed insert). The first pillar is the "economic analysis," which assesses the short- to medium-term influences on price developments, with a focus on the real activity and cost factors (e.g., wages, oil prices) driving prices over these horizons. The focus of this pillar is the interplay of supply and demand in the goods, services, and factor markets.

The second pillar is the "monetary analysis." It exploits the long-run link between money and prices and serves as a "cross-check, from a medium-term to long-term perspective, on the short-term to medium-term assessments derived from the economic analysis" (ECB, 2011, p. 69). This longer-run link between money and inflation was expressed by Issing (2008) as follows: "The close relationship between the money supply and prices has been proven in countless studies all over the globe and all through history... Milton Friedman expressed this insight in a nutshell: [I]nflation is always and everywhere a monetary phenomenon. In his analysis there is no case where a significant change in the quantity of money per unit of output has not been associated with a significant increase in the price level" (p. 105).

The two pillars comprise complementary perspectives of the determinants of inflation (Carboni, Hofmann, and Zampoli, 2010, p. 57). As mentioned, the economic analysis pillar 
seeks to identify risks to price stability at short- to medium-term horizons. The monetary analysis pillar seeks to identify risks to price stability at medium- to long-term horizons. As is the case with the economic analysis, the monetary analysis is broad based in that it takes into account information provided by a wide range of monetary indicators, including interest rates, asset prices, and various definitions of the money supply and their components and counterpartsfor example, credit and several measures of excess liquidity (Carboni, Hofmann, and Zampoli, 2010, p. 57). As the ECB's then-President Jean-Claude Trichet (2006) put it: "[T]he European experience-both before and after the euro-suggests that assigning an important role to money in monetary policy deliberations and communications has, in practice, helped to serve precisely those principles that modern monetary policy literature holds dear...when the economic analysis is complex and its conclusions uncertain, cross-checks with the monetary analysis have proved extremely useful." 16

At the inception of the ECB, that institution announced a "reference value" for monetary growth (ECB, 2001). An aim of the reference value was to help account for the long-run relationship between money and prices. The construction of this reference value followed closely Friedman's construction of a money growth rule. The various monetary aggregates were considered, and ultimately the ECB chose M3, which has demonstrated the "best fit" with prices (Issing, 2008, p.108). M3 is a broad measure of money that consists of currency in circulation plus overnight deposits (M1) plus deposits with agreed maturity of up to two years (M2), plus repurchase agreements plus money market fund shares plus debt securities of up to two years. $\underline{17}$

The ECB then sought to establish a reference value for M3 growth based on gross domestic product (GDP). The trend growth of real GDP was estimated to be between 2 and 2.5 percent per year, and the trend (decline) in velocity was estimated to be between 0.5 and 1.0 percent per year. Based on these estimates and the definition of price stability (annual inflation close to, but below, 2 percent), the ECB set a reference value for M3 growth of 4.5 percent per year.

Several aspects of the M3 reference value are noteworthy. First, the reference value is a medium-term norm rather than a monetary target (ECB, 1999; Issing et al., 2001); deviations of M3 growth from the reference value do not entail a commitment to correct the deviations (Issing, 2008, p. 108). Second, as noted, in addition to the reference value, the monetary pillar is composed of a broad array of monetary and financial market data, including various credit aggregates and interest rates. Third, as discussed above, the M3 reference value is, in part, predicated on a stable M3 demand function. However, for many years following the inception of the euro on January 1, 1999, euro area consumer price inflation was close to 2 percent, with little volatility, while M3 growth was almost always above its reference value, peaking at 12.4 percent (year on year) in late 2007 (Figure 1), implying that the relationship on which the 4.5 percent reference value for M3 growth was based was no longer valid. Hence, the consensus view that emerged from virtually all euro area empirical money demand studies beginning from the early 2000s was that of an unstable M3 demand function (e.g., Beyer, Fischer, and von Landesberger, 2007; Fischer et al., 2007; Fischer and Pill, 2010).

The impact of the finding of an unstable money demand function for the ECB's monetary analysis was highlighted at an ECB conference on "The Role of Money: Money and Monetary Policy in the Twenty-First Century" in Frankfurt in November 2006. At that conference, ECB 


\section{Figure 1}

\section{M3 and HICP Annual Growth Rates}

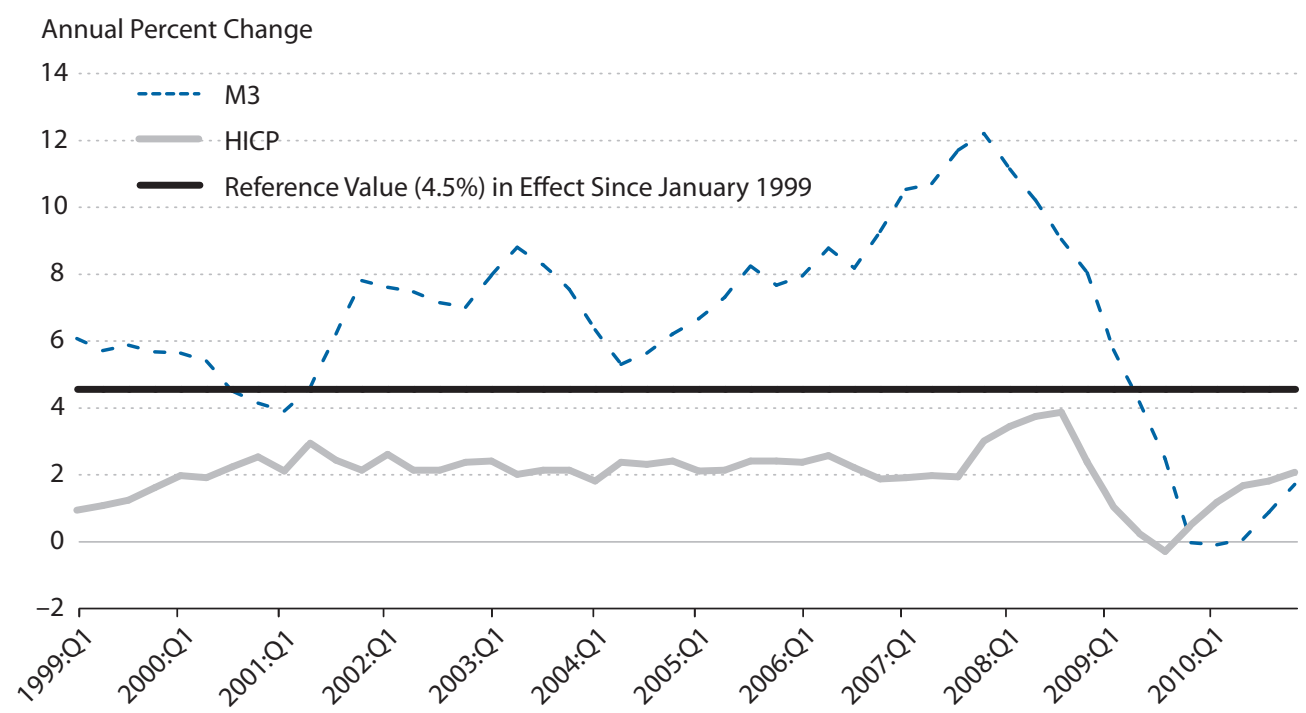

NOTE: HICP, the euro area's Harmonised Index of Consumer Prices.

SOURCE: ECB Statistical Data Warehouse.

staff acknowledged that M3 demand functions had broken down, prompting some commentators to infer that the role of money demand had been downgraded. Thus, the German newspaper Handelsblatt (November 10,2006) reported on the conference proceedings as follows:

The ECB managed to bring together most of the leading academic experts in monetary policy to present papers on and discuss the role of money in monetary policy... The ECB's [staff] presented a paper...in which [the staff] presented some hitherto unpublished information about the development of monetary analysis within the ECB. The paper...contained a comparison of the accuracy, bias and volatility of inflation forecasts derived from monetary and other indicators... [The staff] stressed that the ECB had found money demand not to be stable and had consequently downgraded the role of money demand functions in its analysis.

In the November 10, 2006, Financial Times, Atkins (2006) reported on the same conference as follows:

The ECB’s "monetary pillar," largely inherited from Germany's Bundesbank, is controversial among economists because of confusion about the implications of money supply for inflation. At the ECBhosted conference, prominent officials from the Frankfurt institution made clear that they saw significant scope for refinements...ECB research presented at the conference was open about the shortcomings of the bank's monetary analysis in its eight-year history. $\underline{18}$

Over the past 10 years or so, the ECB has changed the role of the M3 reference value in response to the previously described developments with regard to the demand for money. 
- From 1999 until 2003, the ECB conducted annual reviews of the reference value. Those reviews signaled that the ECB attached importance to the concept of a reference value.

- In order to highlight the medium-term context of the ECB's monetary policy strategy, the annual reviews were discontinued in May 2003 (ECB, 2003). This discontinuation implied that the M3 reference value was assigned a smaller role than it previously had under the monetary analysis pillar.

- Subsequently, the role of the reference value was diminished further. As a result, the ECB presently uses deviations of M3 from the reference value as a "trigger" for "increased efforts to identify and assess the nature and persistence of the forces responsible" (ECB, 2011, p. 80). Effectively, the reference value no longer has any direct impact on ECB decisionmaking.

In light of the importance attached to the finding of an unstable money demand function in the developments described above, the following question arises: How robust is that finding? To address this question, beginning in 2007, the ECB established a research program that created an organizational framework for the "enhancement of [the ECB's] monetary analysis" (Papademos and Stark, 2010, p. 8). Essentially, the enhancement involves (i) a deepening of the monetary analysis pillar through the development of new analytical tools that explore the relationship between monetary trends and underlying inflation dynamics and (ii) a broadening of the monetary analysis pillar to assess the interaction of monetary variables with a wider set of economic and financial factors (Papademos and Stark, 2010, p. 9). In light of the role played by money demand equations in the ECB's monetary analysis pillar, $\frac{19}{}$ one of the major objectives of the enhancement program has been to provide a means for "improving models of euro area money demand" (Papademos and Stark, 2010, p. 8). $\underline{20}$ We provide our contribution to this issue in the next three sections.

\section{THEORETICAL UNDERPINNING}

We consider euro area money demand in the spirit of the framework proposed by Friedman (1956) and Brainard and Tobin (1968). These authors postulated that money, like any asset, yields a flow of services to the agents who hold it. As under the usual theory of consumer choice, Friedman (1956, p. 4) argued that the demand for money depends on three major sets of factors: (i) total wealth - the analog of the budget constraint and composed of both nonhuman capital and human capital; (ii) the price of, and return to, wealth $\frac{21}{1}$; and (iii) the tastes and preferences of the wealth-owning units. He also argued that the proportion of wealth held as money is likely to be affected by the level of uncertainty. Friedman wrote: "[I]t seems reasonable that, other things the same, individuals want to hold a larger fraction of their wealth in the form of money when they are subject to unusual uncertainty than otherwise. This is one of the major factors explaining a frequent tendency for money holdings to rise relative to increases in income during wartime" (1956, pp. 8-9).

Brainard and Tobin (1968) and Tobin (1969) also stressed the role of wealth in the money demand function. These authors argued that, in contrast to conceptual approaches that treat income and wealth interchangeably as determinants of money demand, an increase in wealth 


\section{Hall, Swamy, Tavlas}

results in increases in the demand for all assets, whereas an increase in income increases the demand for money at the expense of other assets. Therefore, both income and wealth belong in the money demand function. We follow the Brainard-Tobin approach in this paper. 22

Specifically, we use a portfolio balance model to estimate the demand for money. Assuming that the asset choices of investors involve money and equities, the demand for real money balances can be written as follows (where the positive and negative symbols above the explanatory variables indicate the expected direction of influence on real money balances):

$$
m-p=f\left(\begin{array}{l}
++ \\
y, w
\end{array} r^{m}-\dot{p}^{e}, r^{e}-\dot{p}^{e}, \text { lesi }\right),
$$

where $m$ is the log of nominal M3, $p$ is the log of the price level, $y$ is the log of real income, $w$ is the log of the real value of wealth, $r^{m}$ is the own rate of return on money, $\dot{p}^{e}$ is the expected inflation rate, $r^{e}$ is the opportunity cost of holding money balances, and, reflecting Friedman's (1956) emphasis on the role of uncertainty on money demand, lesi represents investors' confidence (defined below). In equation (1), real rates of return are approximated by nominal rates minus the expected inflation rate.

We also assume rate of return homogeneity of degree zero, implying that, if all rates of return change by $x$ percent, real quantities of assets in investors' portfolios relative to real income and real wealth will not change. Thus, only rate of return differentials affect money demand. Rate of return homogeneity implies that we can use interest differentials, selecting one of the assets as a numeraire; we use $m$ as a numeraire. Therefore, the money demand function can be rewritten as

$$
m-p=f\left(\begin{array}{l}
++ \\
y, w, r^{e}-r^{m}, \text { lesi }
\end{array}\right) .
$$

When $f$ is semi-log linear, the money demand function becomes

$$
m-p=a_{0}+a_{1} y+a_{2} w+a_{3}\left(r^{e}-r^{m}\right)+a_{4} l e s i+u,
$$

where $u$ is an added error term.

We would expect this scale effect to have long-run unit elasticity, which would imply that the coefficients on income and wealth should sum to unity. Reparameterizing this elasticity into an income variable and a wealth-to-income ratio variable makes it easy to test or impose this effect, as now the coefficient on income is the scale effect (which should be unity) and the coefficient on the ratio of wealth to income captures the effect when income and wealth move separately. This reparameterization is not a restriction on the model until we impose the unit effect; it is simply an easier way of expressing the same thing. Thus, adding and subtracting $a_{2} y_{t}$ on the right-hand side of equation (3) gives

$$
m-p=a_{0}+a_{1}^{\prime} y+a_{2}(w-y)+a_{3}\left(r^{e}-r^{m}\right)+a_{4} l e s i+u,
$$

where $a_{1}^{\prime}=a_{1}+a_{2} \cdot \underline{\underline{23}}$ 


\section{METHODOLOGY}

In the empirical analysis, we use two quite distinct methodologies, one that is now well established in the literature and one that is relatively novel. The first technique is the well-known VEC approach, which involves testing for cointegration in the usual way and then building a dynamic system of cointegrated equations (Johansen, 1995; Davidson and Hall, 1991). The second approach uses the concepts of generalized cointegration (Hall, Swamy, and Tavlas, 2012a) and TVC estimation (see Swamy et al., 2010); this approach allows for consistent estimation of models in the presence of an unknown true functional form, omitted variables, and measurement errors. We present intuitive descriptions of the two approaches in the following subsections.

\subsection{The VEC Methodology}

The VEC methodology has become a workhorse of empirical research (see Cuthbertson, Hall, and Taylor, 1991, and Greene, 2008, among others). This approach aims to identify a set of variables which, together, form a stable long-run relationship. If such a relationship is found to exist, the variables are said to cointegrate. $\underline{\underline{24}}$ This methodology is, therefore, of particular relevance to the task at hand here since the existence, or absence, of cointegration essentially determines the existence of a satisfactory and usable money demand function. Such methodology is, however, limited in certain ways by its basic setup. Cointegration has been largely developed within a linear (or log-linear) framework and so it cannot easily allow for other (nonlinear) functional forms, unless the precise nonlinear functional form happens to be known. Moreover, if an important variable is missing from the set of variables under consideration, then the researcher may conclude that there is no cointegration. This finding, of course, may be true about the set of variables under consideration, but it may not be true of the real world. For example, a researcher may test to find whether cointegration exists among three variables-say, real money balances, real income, and wealth - and find that those three variables do not cointegrate. The researcher might then conclude that a stable relationship among these variables does not exist. Insofar as there may exist a fourth variable whose inclusion with the other three variables would have provided a cointegrating relationship, the researcher's inference on the basis of just the three variables would have been misleading. In other words, we might find no cointegration among a set of variables and conclude that there is no stable money demand function. However, this finding may simply indicate that we have not found the appropriate set of variables and that, in fact, money demand is stable. Consequently, much of the work in the VEC tradition becomes a search for a suitable set of variables that both cointegrates and provides a good model of the relationship under consideration.

\subsection{Generalized Cointegration and TVC Estimation}

The other approach we use is less well known and so we provide an intuitive account of the ideas used; we also provide references to a formal exposition. Both generalized cointegration and TVC estimation proceed from an important theorem first established by Swamy and Mehta (1975), which has subsequently been confirmed by Granger (2008). This theorem states that any nonlinear functional form can be exactly represented by a model that is linear in variables but has TVCs. The implication of this result is that, even if we do not know the correct functional 


\section{Hall, Swamy, Tavlas}

form of a relationship, we can always represent this relationship as a time-varying parameter relationship and, hence, estimate it.

This theorem underlies the concept called generalized cointegration (Hall, Swamy, and Tavlas, 2012b), which relaxes some of the stringent assumptions of standard cointegration analysis. In particular, generalized cointegration does two things. First, it allows for the possibility that we may have important omitted variables. Second, it allows for the possibility that we may have misspecified the functional form we are estimating. That is, using generalized cointegration we are able to estimate unbiased relationships among a set of variables even if (i) we do not know the true, underlying functional form and (ii) there are missing variables. To return to the previous example of a money demand function consisting of just three variables (real money balances, an interest rate, and wealth), generalized cointegration works by estimating a relationship that does not contain specification errors (such as omitted variable biases).

Underlying generalized cointegration is a new way of thinking about, and testing for, cointegration that emphasizes the properties of the real world rather than a particular model. If, in the real world, a causal cointegrating vector exists that determines a variable (say, money), then obviously, if one of the variables (say $X$ ) in that relationship changes, money will also change. This implies that the partial derivative of money with respect to $X$ is nonzero. Thus, if we had a way of obtaining consistent estimates of this partial derivative and testing to determine if it is indeed nonzero, this would give us a way to test for the presence of cointegration in the real world (rather than just among an arbitrary set of variables). So, we might be able to assert that there is a stable money demand function in the real world, even though we do not know its exact functional form and/or all the variables that comprise that relationship. This would still be a very useful statement from a policy perspective, although, obviously, not as useful as knowing the complete form of that relationship.

Of course, such a supposition is asking a great deal of an estimation technique. However, that is precisely what TVC estimation aims to provide (Swamy et al., 2010). This technique builds on the Swamy and Mehta (1975) theorem mentioned above, where it turns out that the TVCs in a model without omitted variables or measurement error are consistent estimates of the partial derivatives of the unknown nonlinear functional form. So, in the absence of other misspecification testing, the significance of the TVCs would be equivalent to testing for generalized cointegration.

Swamy et al. (2010) show exactly what happens to the TVCs as other forms of misspecification are added to the model. If we allow for the presence of some omitted variables from the model, then the true TVCs become contaminated by a term that involves the relationship between the omitted and included variables. Also, if we allow for measurement error, then the TVC is further contaminated by a term that allows for the relationship between the exogenous variables and the error terms. Thus, as one might expect, the estimated TVC is no longer a consistent estimate of the true partial derivatives of the nonlinear function but is now biased due to the effects of omitted variables and measurement error. There are exact mathematical proofs provided for our statements up to this point.

Some parametric assumptions are needed to make TVC estimation fully operational. $25 \mathrm{We}$ make two key assumptions: First, we assume that the TVCs themselves are determined by a set of stochastic linear equations, which makes them a function of a set of variables that we call 
driver (or coefficient driver) variables. This is a relatively uncontroversial assumption. Second, we assume that some of these drivers are correlated with the misspecification in the model and some are correlated with the time variation emanating from the nonlinear (true) functional form. With this assumption we can then simply remove the bias from the TVCs by removing the effect of the set of coefficient drivers that are correlated with the misspecification. This procedure, then, yields a consistent set of estimates of the true partial derivatives of the unknown nonlinear function, which may then be tested by constructing $t$-tests in the usual way. An important difference between coefficient drivers and instrumental variables is that a valid instrument requires a variable that is uncorrelated with the misspecification, which often proves difficult to find. For a valid driver we need variables that are correlated with the misspecification and we would expect that this is much easier to achieve.

These consistent (or bias-free) estimates may then be used to test for generalized cointegration, even in the presence of omitted variables. It is important to stress precisely what is being claimed here-as well as what is not. This test aims to tell us whether or not there is cointegration in the real world-that is, whether there actually exists a stable function determining the variable of interest. It does not, however, tell us the complete form of that relationship or what the missing variables might be.

\section{ESTIMATION}

\subsection{Data}

We used the following variables as defined here. Real money balances are broad money (M3) divided by the GDP deflator. Real GDP is used as a proxy for real income. The opportunity cost of holding money is the long-term interest rate minus the own rate of return on M3. Because a long-run interest rate series for the euro area as a whole does not exist for the entire estimation period, which begins with 1980:Q1, we used the rate on 10-year German sovereign bonds for the long-term rate. The series for the own rate of return on M3 was constructed by ECB staff, who provided us with that series. The source of the other above data is the ECB Statistical Data Warehouse, which contains (synthetic) euro area data beginning with 1980:Q1. The estimation periods are the pre-crisis sample (1980:Q1-2006:Q4) and the full sample (1980:Q1-2009:Q4), the latter of which includes the initial stages of the international financial crisis. All variables other than the opportunity cost variable are in terms of logs.

We use two wealth series to capture the effect of wealth on money demand-financial wealth and housing wealth. Financial wealth is total financial assets (currency and deposits, debt securities, shares and mutual fund shares, and insurance reserves) held by households and nonprofit institutions serving households. Original series are from the euro area quarterly sectoral accounts for the period since 1999 (these are available at a quarterly frequency), from the European Monetary Union financial accounts for the period 1995-98, and from national sources for the period 1980-94.

Housing wealth is total housing held by households and nonprofit institutions serving households. Housing wealth data are at current replacement costs net of capital depreciation based on ECB estimates. Both series refer to the euro area at a fixed composition of 15 members. For periods before the introduction of the euro, the respective irrevocable exchange rates have been 


\section{Figure 2}

\section{Log of Income Velocity (M3)}

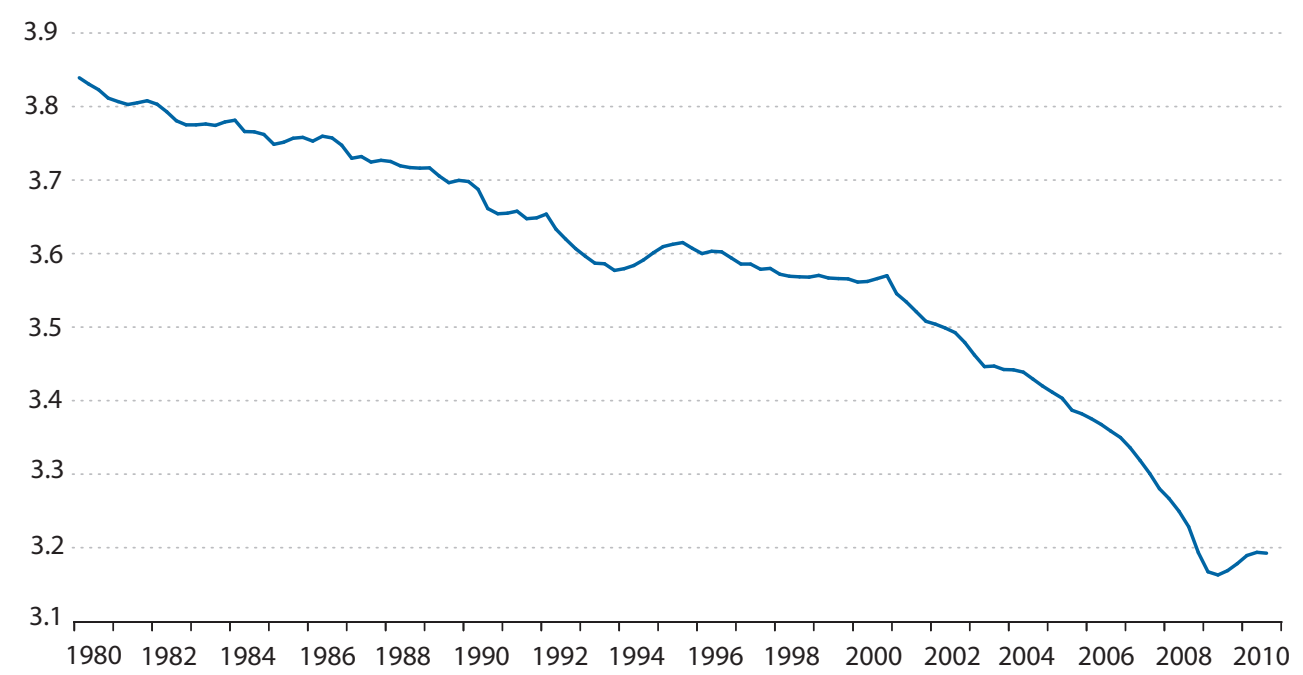

used. The two wealth series and the opportunity cost series were provided by ECB staff; the two wealth measures are available only on an annual basis; we interpolated these data to a quarterly frequency using a cubic spline.

Why include the two measures of wealth separately rather than a composite wealth variable? After all, the money demand theory described above includes only a single aggregate measure of wealth. $\underline{26}$ However, as we show below, financial wealth has been more volatile than housing wealth. Given that the volatility properties of the two measures of wealth have been quite different, it seems reasonable to hypothesize that the effects of the two components of wealth on money demand might differ. For example, if money demand responds to permanent income and wealth, then short-term movements in financial markets may have a very different impact on an individual's perceived wealth than short-term movements in the housing market. In any case, the issue is empirical and is addressed in the results presented below.

\subsection{VEC Results}

As a point of departure, we begin by specifying a general vector autoregressive (VAR) model and then reparameterize this model into a VEC model. $\underline{27}$ This approach allows us to both test and impose the appropriate cointegrating rank on the system. $\stackrel{28}{ }$ Figures 2 and 3 illustrate a problem encountered in estimating euro area money demand with the above data. Figure 2 shows the velocity of M3 during 1980:Q1-2009:Q4. Velocity shows a clear downward trend, which is normally explained by the growth in wealth (housing and financial) relative to total income. However, at the end of the period velocity clearly reverses course and moves upward.

Figure 3 focuses on the period 2005:Q1-2010:Q4; the figure shows the annualized growth rates of real money, real income (i.e., real GDP), and the financial wealth-to-GDP and housing wealth-to-GDP ratios. As would be expected, GDP and the wealth ratios typically sum to about 


\section{Figure 3}

\section{Growth Rates of M3, Wealth, and Real Income}

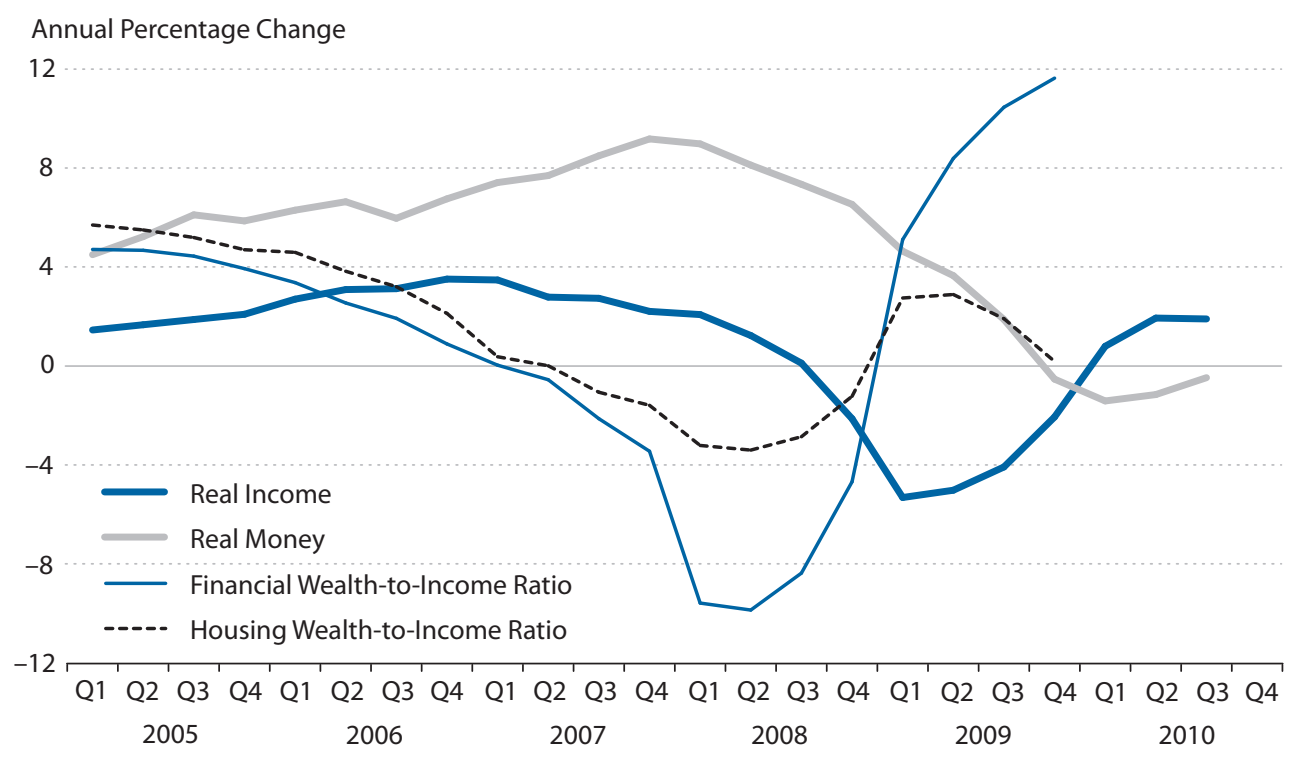

Table 1

Estimation of Euro Area Money Demand (1980:Q4-2006:Q4)

Panel A: Test of cointegration

\begin{tabular}{lcccc} 
Hypothesized no. of CEs & Eigenvalue & Trace statistic & $\mathbf{0 . 0 5}$ Critical value & Probability** \\
\hline None* $^{*}$ & 0.285051 & 72.79355 & 47.85613 & 0.0001 \\
At most 1* & 0.202307 & 37.56147 & 29.79707 & 0.0052 \\
At most 2* & 0.122488 & 13.82815 & 15.49471 & 0.0878 \\
At most 3 & 0.001031 & 0.108303 & 3.841466 & 0.7421
\end{tabular}

Panel B: The two identified cointegrating vectors

\begin{tabular}{lrr} 
& \multicolumn{2}{c}{ Cointegrating equation } \\
\cline { 2 - 3 } Variable & \multicolumn{1}{c}{$\mathbf{2}$} \\
\hline$m-p$ & -1.000000 & 0.000000 \\
$y$ & 1.000000 & -1.000000 \\
$w f-y$ & 0.675699 & 1.002571 \\
$w h-y$ & 0.013909 & 0.111447
\end{tabular}

NOTE: All variables are in logarithms. ** and * indicate significance at the 5 percent and 10 percent levels, respectively. CE, cointegrating equation. Variables are defined as follows: $m-p$ is M3 divided by the GDP deflator; $y$ is real GDP; $w f-y$ is the financial wealth-to-real GDP ratio; $w h-y$ is the housing wealth-to-real GDP ratio. 


\section{Hall, Swamy, Tavlas}

the same growth rate as real money, but from 2007:Q1 through 2008:Q4, the growth rate of money exceeds the sum of the other variables-and by considerable amounts. Clearly, something besides wealth and income is having an impact on real money balances during the latter period.

Another way to illustrate this argument is to test whether the variables real money, real GDP, and the two wealth-to-GDP ratios cointegrate. To determine whether there is cointegration, we have (i) used normalization restrictions on money and real GDP (i.e., we put real money balances on the left-hand side of the first cointegrating vector, and we put real GDP on the left-hand side of the second cointegrating vector), (ii) imposed the income effect in the money equation to be unity, and (iii) excluded money from the GDP equation (i.e., the second cointegrating equation). Consider first 1980:Q1-2006:Q4-the period ending just before the outbreak of the international financial crisis. As reported in Table 1, there are at least two cointegrating vectors over this period. However, extending the data sample by three years—that is, 2007:Q1-2009:Q4—suggests there is no cointegration among the same four variables. ${ }^{29}$ The failure to cointegrate over the extended sample period is reflected in Figures 4 and 5, which show the recursive residuals and the standard cumulative sum (CUSUM) test. $\frac{30}{3}$ Both tests clearly show that the model is stable up to around 2006 but then it becomes highly unstable over the remainder of the period.

\subsection{The Role of Confidence}

What happened over this latter period? One possibility is that the crises in the international financial system caused a flight into money. Specifically, heightened uncertainty may have led to an increase in the precautionary demand for money, a safe asset. In this regard, an issue that arises is whether we can measure this uncertainty effect with reasonable accuracy.

Although earlier writers such as Friedman (1956) stressed the role of confidence in their discussions of money demand, they were not able to use measures of confidence in their applied work because relatively long time series on measures of confidence were unavailable to them. This situation has carried over-to the best of our knowledge-to all subsequent empirical work, despite the fact that time-series indicators of confidence have become available for most economies since the early 1990s, if not earlier. To capture the effect of confidence on euro area money demand we used the euro area economic sentiment indicator (ESI) compiled by the European Commission service. The ESI is a composite indicator made up of five sectoral confidence indicators with different weights: industrial confidence (40 percent), services confidence (30 percent), consumer confidence (20 percent), construction confidence ( 5 percent), and retail trade confidence (5 percent). The ESI is available on a monthly frequency from 1986:01. For this study, it was converted to a quarterly frequency. $\frac{31}{\text { Figure }} 6$ plots the level of the ESI. As shown there, the series on confidence tends to exhibit wide swings; it is nonstationary but nonetheless exhibits mean-reverting behavior. $\frac{32}{}$ Of particular interest is the sharp decline in the ESI that began in early 2007 and persisted through the end of 2008. During the financial crises, the sentiment indicator fell from a peak of 110 to about 70 , a fall of around 36 percent.

We now turn to the formal VEC analysis with the confidence effect for the full sample period (1980:Q1-2009:Q4). As above, we construct a VAR system with the I(1) variables forming a vector of four endogenous variables: real money balances $(m-p)$, real GDP $(y)$, the ratio of real housing wealth to real GDP $(w h-y)$, and the ratio of real financial wealth to real GDP $(w f-y)$. The log of the ESI index (lesi) was treated as an exogenous variable in the VEC system under the 


\section{Figure 4}

\section{Recursive Residuals of the Cointegrating Vector}

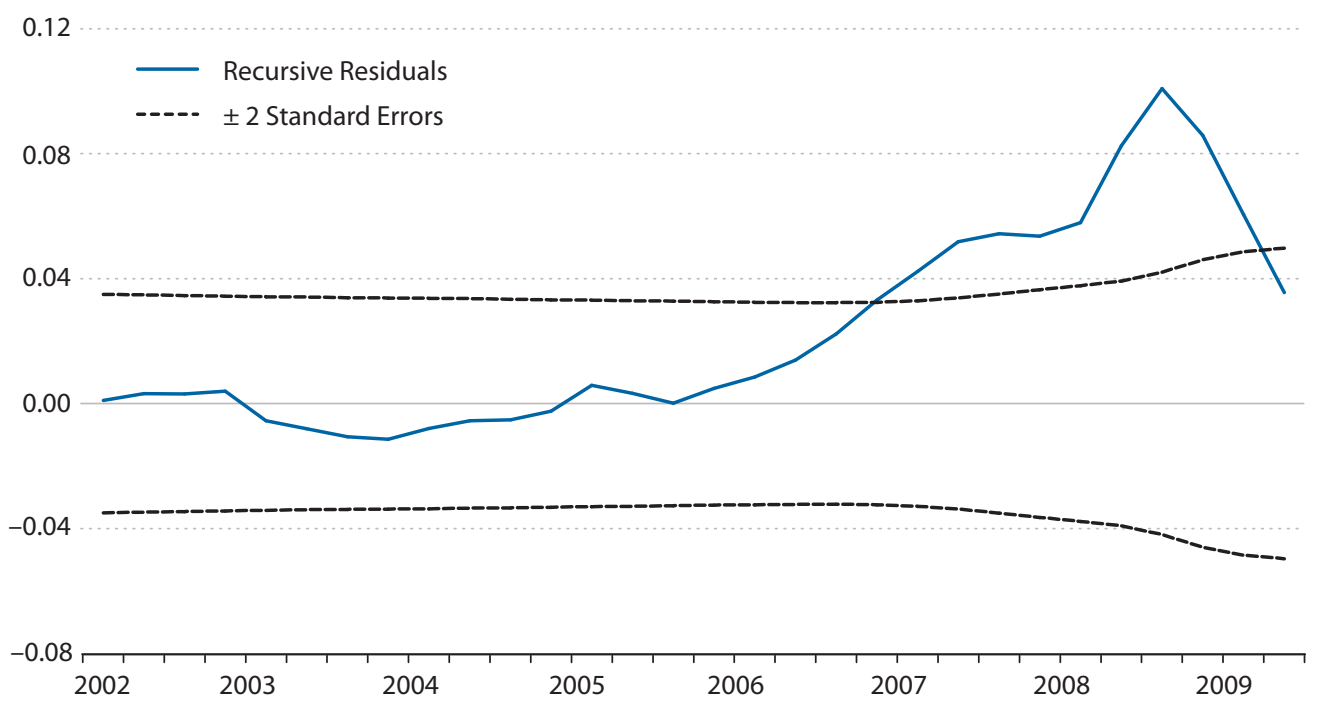

\section{Figure 5}

\section{Stability Test}

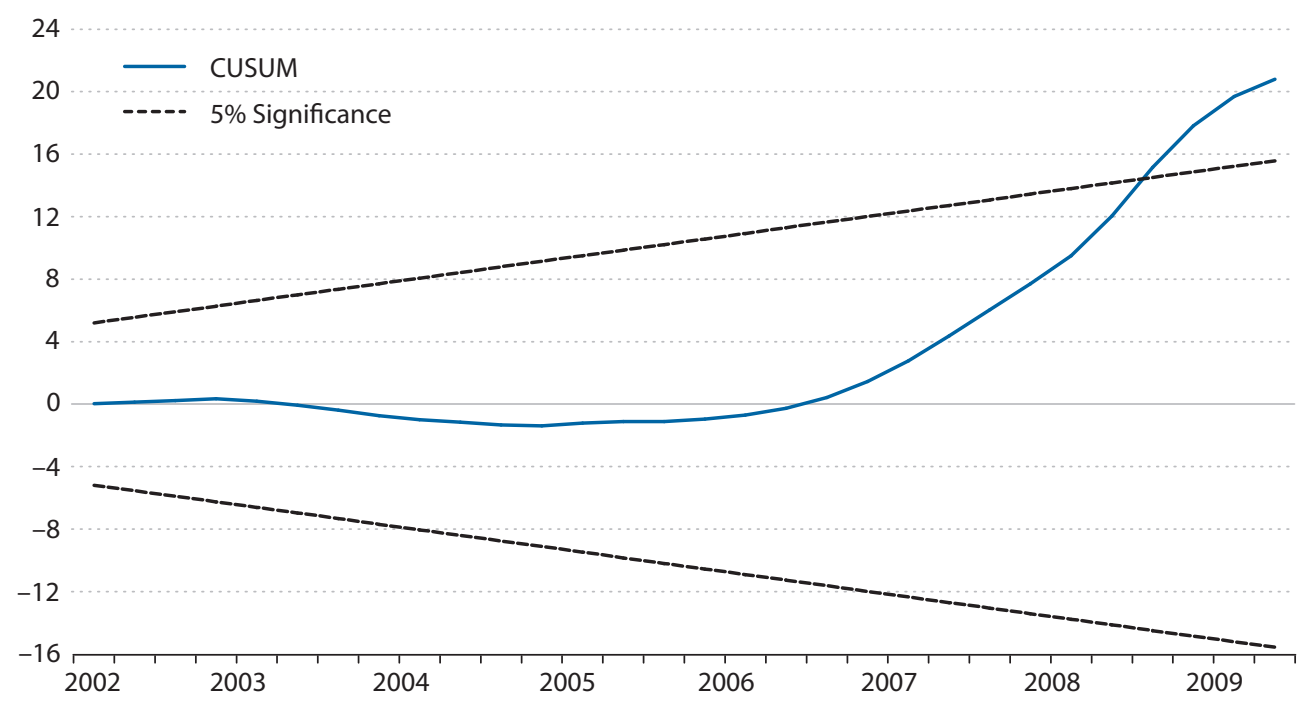

NOTE: CUSUM, cumulative sum. 


\section{Figure 6}

\section{Euro Area Economic Sentiment Indicator (long-term average = 100)}

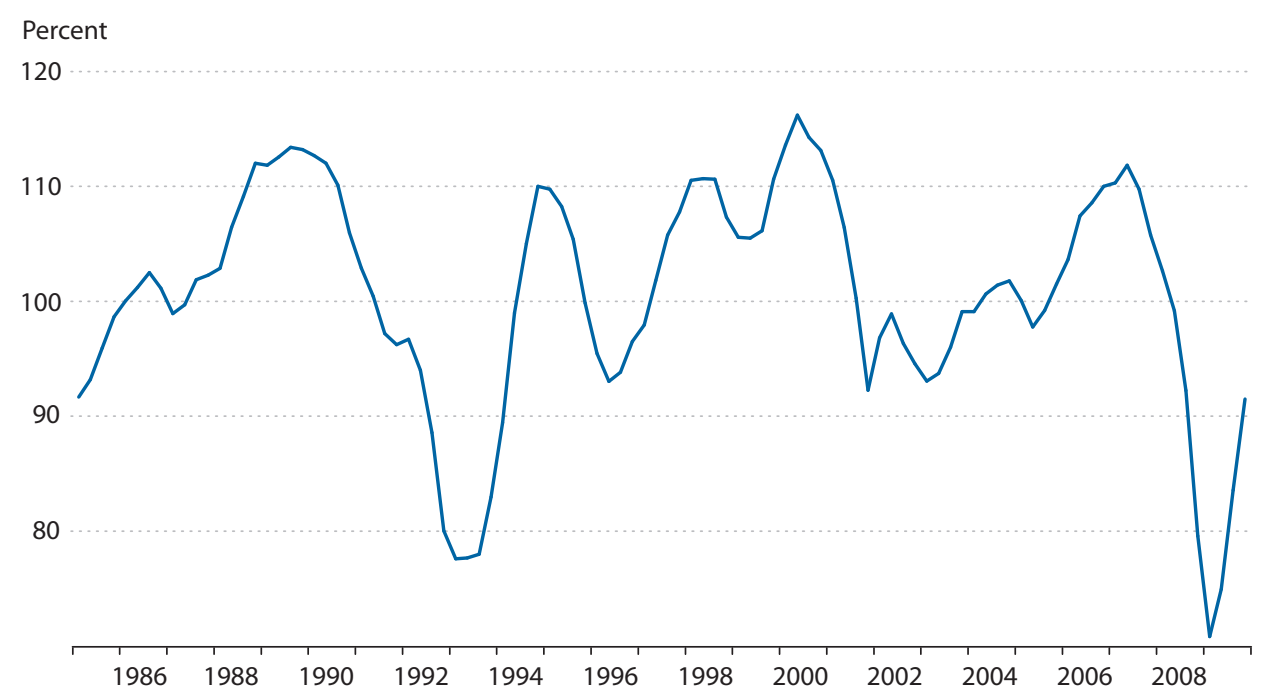

(reasonable) presumption that confidence is typically affected by overall economic and financial conditions, and not by real money balances. The spread between the 10-year German bond rate and the own rate on money $(r 10-r m)$ is not in the cointegrating vector, as it is stationary, but it is in the dynamics at lag minus 1 to line up with the cointegrating vector; the spread may be reinterpreted as part of the long-run solution. Following our previous procedure, we also included a split time trend and a shift dummy starting in 2002 to the end of the sample as a proxy for the change in behavior that occurred after the introduction of the euro; both dummy variables are lagged one period to line up with the error correction mechanism.

The number of cointegrating relationships in the system was tested using the Johansen procedure (Johansen, 1995). These results are reported in Table 2, which shows that at a 1 percent significance level there are two cointegrating vectors. The table shows the just-identified vectors where again we have (i) used normalization restrictions on money and real GDP (i.e., we put real money balances on the left-hand side of the first cointegrating vector and we put real GDP on the left-hand side of the second cointegrating vector), (ii) imposed the income effect in the money equation to be unity, and (iii) excluded money from the GDP equation (i.e., the second cointegrating equation). The finding of two cointegrating vectors is an important result in itself because it illustrates that with the confidence variable we now have cointegration for the entire period. Thus, the model does not break down by including the crises period as it did when the confidence variable was not included. The error correction coefficient on the first cointegrating vector is significant (the $t$-ratio is 4.7), correctly signed, and reasonably large (0.16), and the

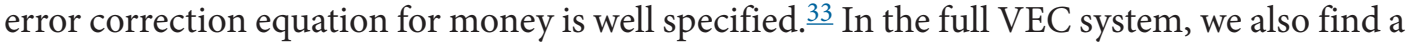
fairly large role for the interest rate differential variable.

What type of role does confidence play? The long-run effect of the confidence variable is -0.037 . Given the 36 percent decline in the confidence indicator during 2007 and 2008, the esti- 


\section{Table 2}

Estimation of Euro Area Money Demand (1980:Q1-2009:Q4)

\section{Panel A: Test of cointegration Hypothesized no. of CEs}

None*

At most $1^{*}$

At most $2^{*}$

At most 3

Eigenvalue

0.381902

0.187033

0.126006

0.006415

\section{Trace statistic}

97.02697

40.73725

16.51067

0.752930
0.05 Critical value

47.85613

29.79707

15.49471

3.841466
Probability**

0.0000

0.0019

0.0351

0.3855

Panel B: The two identified cointegrating vectors

\begin{tabular}{lcc} 
& \multicolumn{2}{c}{ Cointegrating equation } \\
\cline { 2 - 3 } Variable & \multicolumn{1}{c}{$\mathbf{2}$} \\
\hline$m-p$ & -1.000000 & 0.000000 \\
$y$ & 1.000000 & -1.000000 \\
$w f-y$ & 0.38 & 0.642 \\
$w h-y$ & 0.44 & 0.53 \\
lesi & -0.0337 & 0.00 \\
R10-rm & -1.62 & 0.0 \\
Constant & 1.437 & 17.24
\end{tabular}

NOTE: All variables are in logarithms. ** and * indicate significance at the 5 percent and 10 percent levels, respectively. CE, cointegratin equation. Variables are defined as follows: $m-p$ is M3 divided by the GDP deflator; $y$ is real GDP; $w f-y$ is the financial wealth-to-real GDP ratio; $w h-y$ is the housing wealth-to-real GDP ratio; lesi is the euro area economic sentiment indicator; R10-rm is the interest rate on 10-year German government bonds minus the own rate on money.

mated coefficient of the confidence variable in the cointegrating vector suggests that this would have caused an increase in the demand for money of about 1.3 percent based on the precautionary effects discussed previously. For much of the 2007:Q1-2008:Q4 period, the growth rates of income and the two wealth variables were negative, which acted to reduce the demand for money. Therefore, the confidence effect helps to explain why real money growth, which was falling during those two years, nevertheless remained positive. In 2009 the confidence index reversed course and increased from about 70 to about 90 (see Figure 6). What happened to real money? Figure 2 shows income velocity rose in 2009; alternatively, real money balances declined (see also Figure 3). This dynamic is as expected-a rise in confidence should decrease the demand for money. Moreover, the decline in real money took place during a time when both real income and financial wealth jumped upward, which, everything else held equal, should have increased real money demand.

Figures 7 and 8 report the recursive residuals (from an ordinary least squares static regression) from the money cointegrating vector and the CUSUM test applied to this equation. These residuals should be contrasted with those in Figures 4 and 5, which show the corresponding residuals without the confidence variable. Both procedures illustrate that the money demand equation is now stable through the complete period of the crises. 
Hall, Swamy, Tavlas

\section{Figure 7}

\section{Stability of the Enlarged Model}

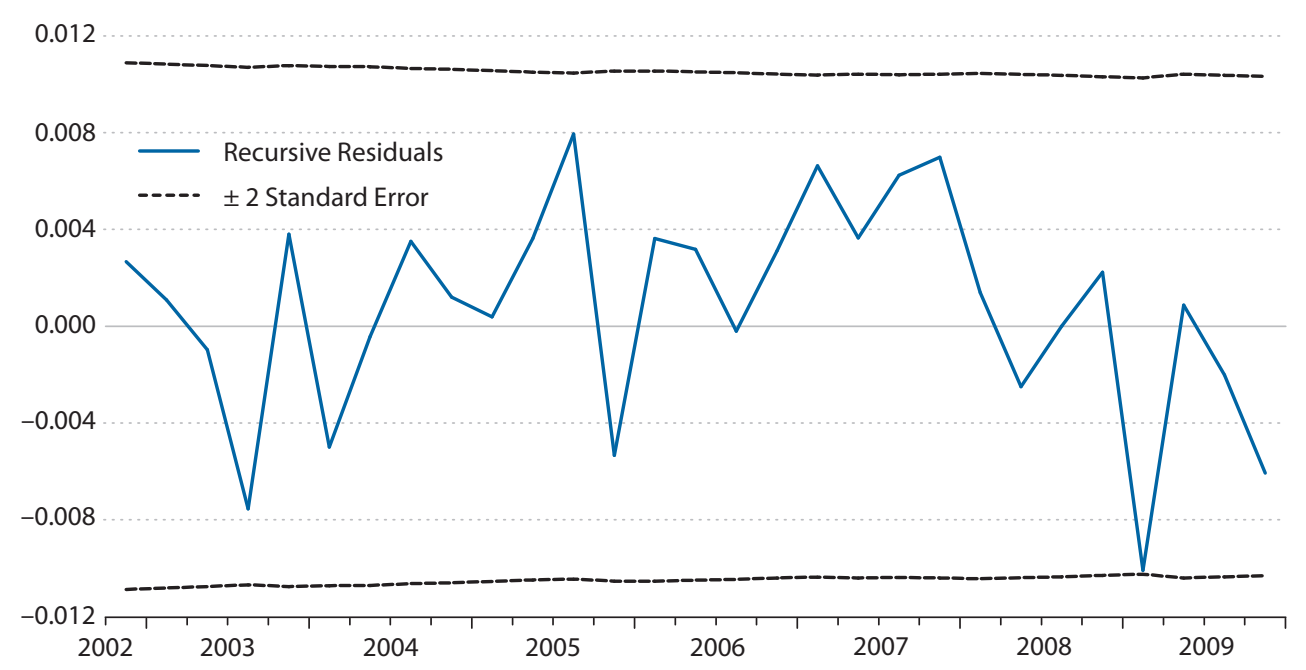

Figure 8

The CUSUM Test for the Enlarged Model

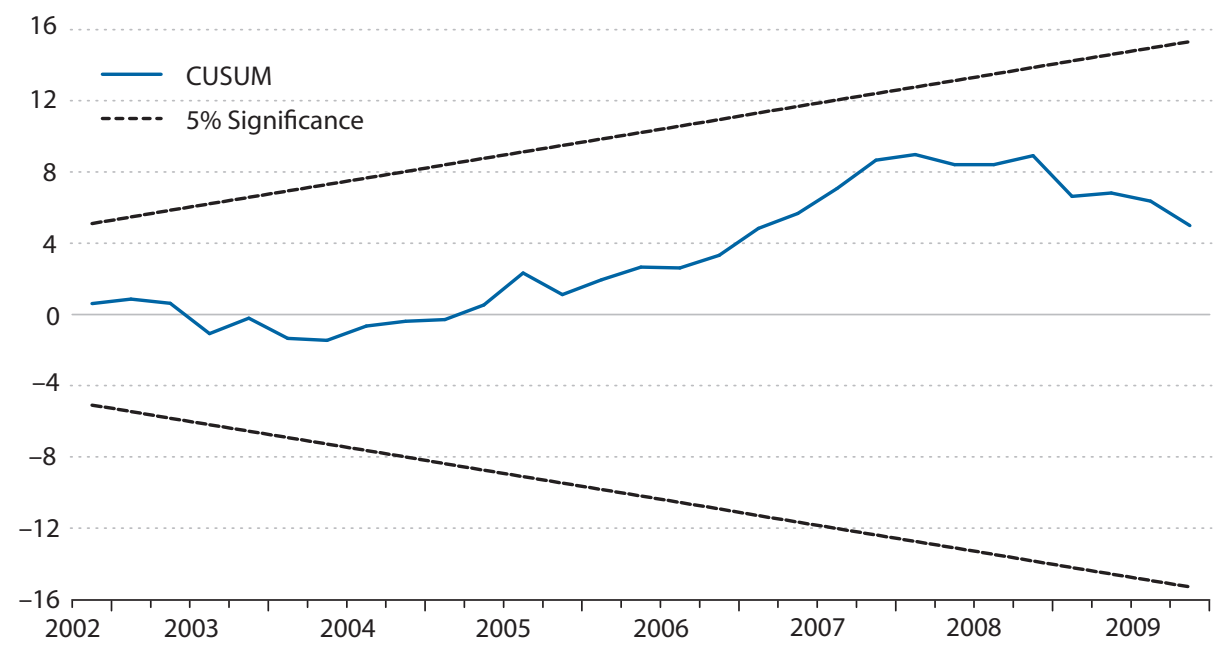

NOTE: CUSUM, cumulative sum. 


\section{Table 3}

\section{TVC Estimation of Long-Run Money Demand for the Euro Area}

\section{Variables}

Constant

$y$

$w f-y$

wh-y

lesi

R10-rm

$\bar{R}^{2}$
Total effects ( 1 )

-4.82
1.21
0.08
0.41
-0.12
-0.1
0.99

Bias-free effects (2)

$$
\begin{aligned}
& -4.8^{* * *}(-2.4) \\
& 1.17^{* * *}(2.1) \\
& 0.09^{* * *}(2.2) \\
& 0.43^{* * *}(2.8) \\
& -0.29^{* * *}(-2.3) \\
& -0.03^{* *}(1.8)
\end{aligned}
$$

0.99

NOTE: All variables except the interest rate are in logarithms. Prob $(F$-stat $)=0.000$. Figures in parentheses are $t$-ratios; $t$-ratios are not presented for the total effects since the coefficients could be subject to specification error. ${ }^{* *}$ and ${ }^{* *}$ indicate significance at the 1 and 5 percent levels, respectively. The estimates in column (1) are obtained using the following coefficient drivers: the constant term, lagged change in real income, lagged change in real money, and change in the difference between the opportunity cost on holding money and the own rate on money. The bias-free effects in column (2) are estimated using three coefficient drivers: the constant term, the lagged change in real income, and the lagged change in real money. Variables are defined as follows: the dependent variable is M3 divided by the GDP deflator; $y$ is real GDP; $w f-y$ is the financial wealth-to-real GDP ratio; wh-y is the housing wealth-to-real GDP ratio; lesi is the euro area economic sentiment indicator; $R 10-r m$ is the interest rate on 10-year German government bonds minus the own rate of return on money.

\subsection{TVC Results}

Next, we estimated the long-run money demand equation using TVC estimation. The equation estimated is

$$
(m-p)_{t}=\alpha_{0 t}+\alpha_{1 t} y_{t}+\alpha_{2 t}(w f-y)_{t}+\alpha_{3 t}(w h-y)_{t}+\alpha_{4 t} l e s i_{t}+\alpha_{5 t}(r 10-r m),
$$

where the coefficients are time varying. It is assumed that for $j=0,1,2,3,4,5$ :

$$
\alpha_{j t}=\pi_{j 0}+\pi_{j 1} z_{1 t}+\pi_{j 2} z_{2 t}+\pi_{j 3} z_{3 t}+\varepsilon_{j t}
$$

where the $\pi$ 's are constants, the $\varepsilon_{j t}$ 's are contemporaneously and serially correlated, $\underline{34}$ and the $z$ 's are the coefficient drivers (in this case, we use the lagged change in real money, the lagged change in GDP, and the lagged opportunity cost variable). In light of the financial crisis beginning in 2007, the total TVCs could be expected to vary considerably at the end of the period but the bias-free coefficients would be expected to remain stable.

Table 3 presents both the (average) total effects and the (average) bias-free coefficients. (Recall, the bias-free estimates are those for which specification errors have been removed. In what follows, we focus on the bias-free estimates. $\frac{35}{}$ ) The (average) income elasticity is $1.17 \underline{36}$; the null hypothesis that this elasticity equals unity cannot be rejected at the 1 percent level. The coefficient on the opportunity cost variable is correctly signed and reasonably large; although somewhat smaller than the VEC estimate, it is significant at the 5 percent level. The coefficient on the financial wealth-to-income ratio is positive and highly significant, as is the coefficient on the housing wealth-to-income ratio. Specifically, the coefficient on the financial wealth-toincome ratio is 0.09 , compared with 0.38 under VEC; the TVC estimate of the bias-free coeffi- 


\section{Hall, Swamy, Tavlas}

cient on the housing wealth-to-income ratio is 0.43 , compared with 0.44 under VEC. Thus, in contrast to the VEC results, the TVC results indicate that the demand for money responds quite differently to changes in financial wealth and changes in housing wealth; changes in housing wealth have a much larger effect on the demand for money than do changes in financial wealth. The sum of the TVC coefficients on the two wealth-to-income ratios is 0.52 , so if the wealth-toincome ratio were to rise by 10 percent, real money demand would be expected to rise by 5.2 percent. Therefore, especially in periods of rapid rises in property values and/or equity prices, the omission of wealth variables in the money demand specification can be a source of instability in that specification.

What about the effect of confidence on money demand? As reported in Table 3, the coefficient on the confidence variable is -0.29 and is significant; thus, a 1 percent decline in confidence increases the demand for money by 0.29 percent. An implication of this result is that the sharp decline in confidence observed during 2007-09 (shown in Figure 6) contributed to an increase in the demand for money during that period. As mentioned previously, the confidence index fell by about 36 percent in 2007 and 2008. Everything else remaining the same, this decline in confidence would have led to about a 10 percent increase in money demand, which helps to explain why real money growth remained high during the crisis years. In 2009, the growth of real money balances declined sharply (see Figure 3), and income velocity suddenly increased (see Figure 2). Why did the growth of money demand decline? As shown in Figure 3, the growth of both real income and financial wealth turned sharply positive in 2009 , while housing wealth was little changed. On balance, therefore, these factors should have caused a rise in the growth of real money balances. Yet, the growth of real money balances declined. The sharp rise in confidence explains this occurrence very well.

Figures 9 through 13 present the time profiles of the total effect and the bias-free effect yielded by TVC estimation for the five variables - real GDP, the financial wealth-to-income ratio, the housing wealth-to-income ratio, the confidence variable, and the interest rate, respectively. A striking feature of these results is that the bias-free effect can be much more stable than the total effects; see Figure 10, which reports the coefficients on the financial wealth-to-income ratio. Another important feature is that some of the total TVCs exhibit a strong instability in the past few years, which is completely eliminated in the bias-free component. This again is consistent with the VEC result that confidence effects seem to have been very important over this period.

\subsection{Comparing the Empirical Methodologies}

The generalized, nonlinear cointegration technique by and large confirmed the results of the widely used linear VEC technique. Nevertheless, there are some differences, as noted below:

- Under the VEC technique, the sum of the two wealth coefficients was 0.82 and the individual coefficients -0.38 for financial wealth and 0.44 for housing wealth-were similar. Under the TVC procedure, the sum of the wealth coefficients was 0.52 , and the individual coefficients were quite different- 0.43 for the ratio of housing wealth to GDP and 0.09 for the ratio of financial wealth to GDP. Consequently, the TVC results support our earlier conjecture that, because changes in financial wealth tend to be more volatile-or less sustainable-than housing wealth, the changes in the former have a lesser impact on the 


\section{Figure 9}

TVC Estimation of the GDP Coefficient

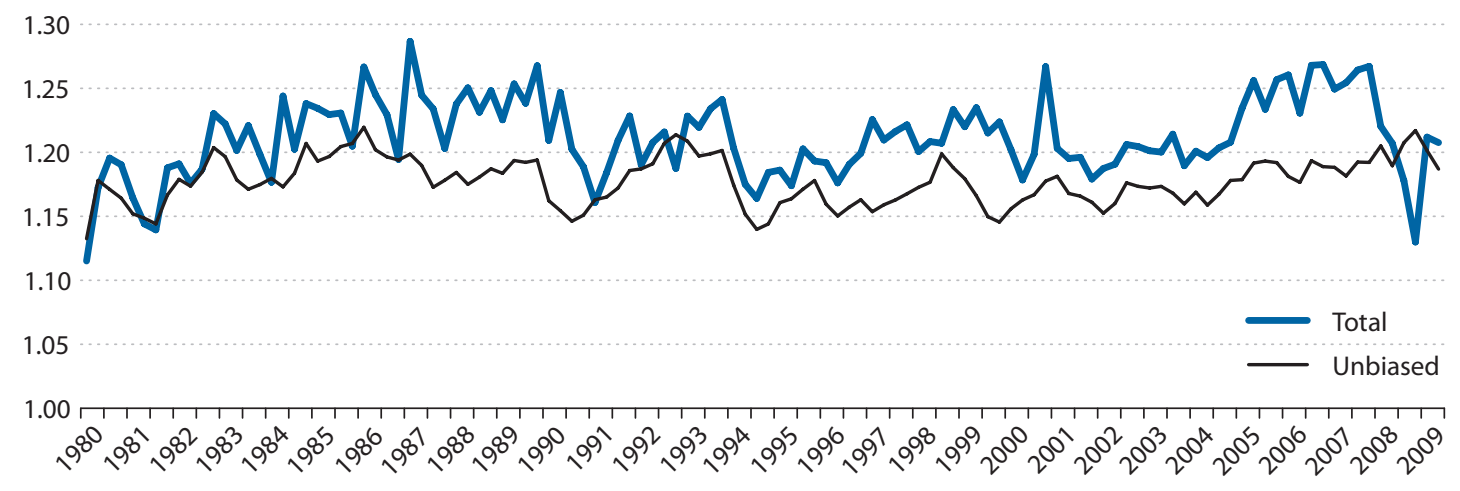

Figure 10

TVC Estimation of the Financial Wealth-to-Income Ratio

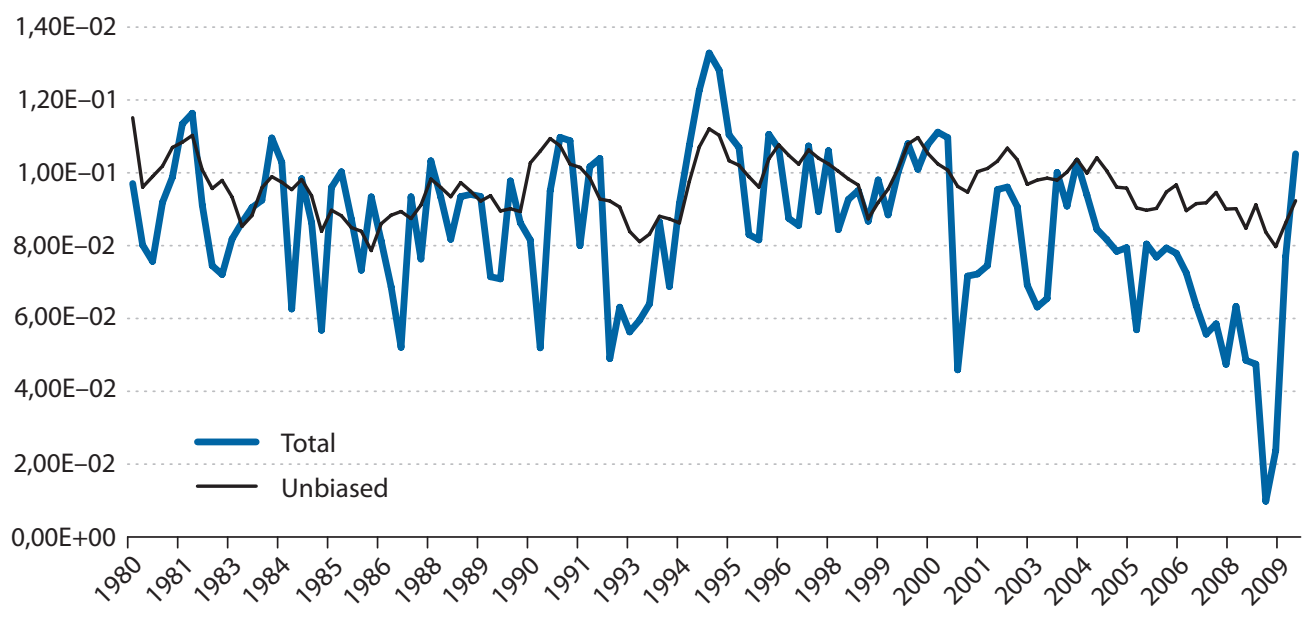




\section{Figure 11}

TVC Estimation of the Housing Wealth-to-Income Ratio

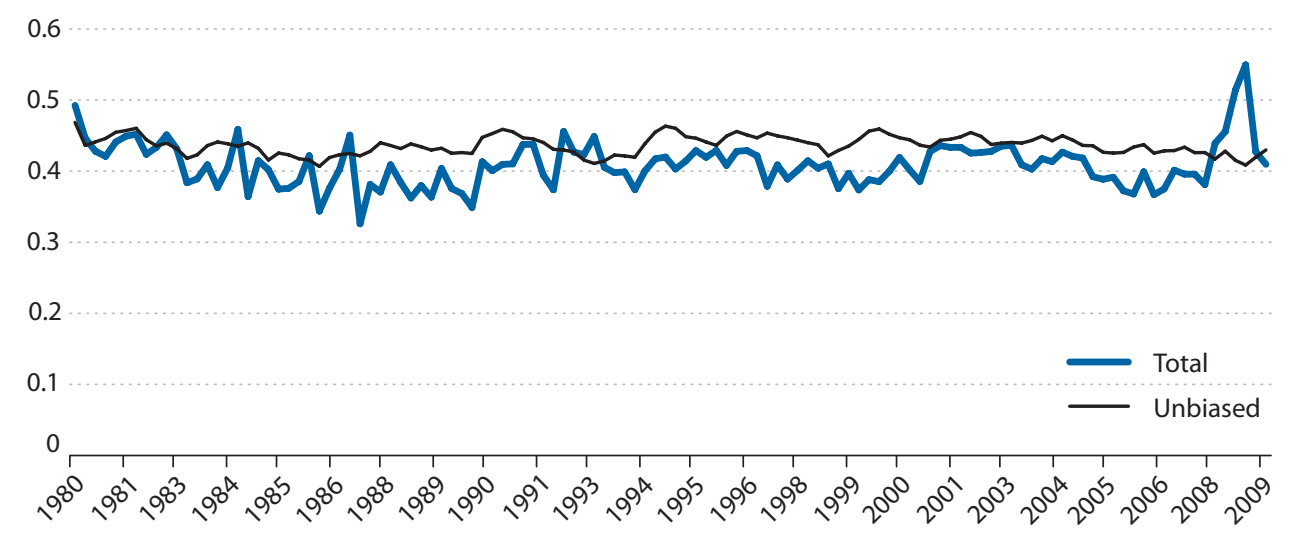

Figure 12

TVC Estimation of the Confidence Effect

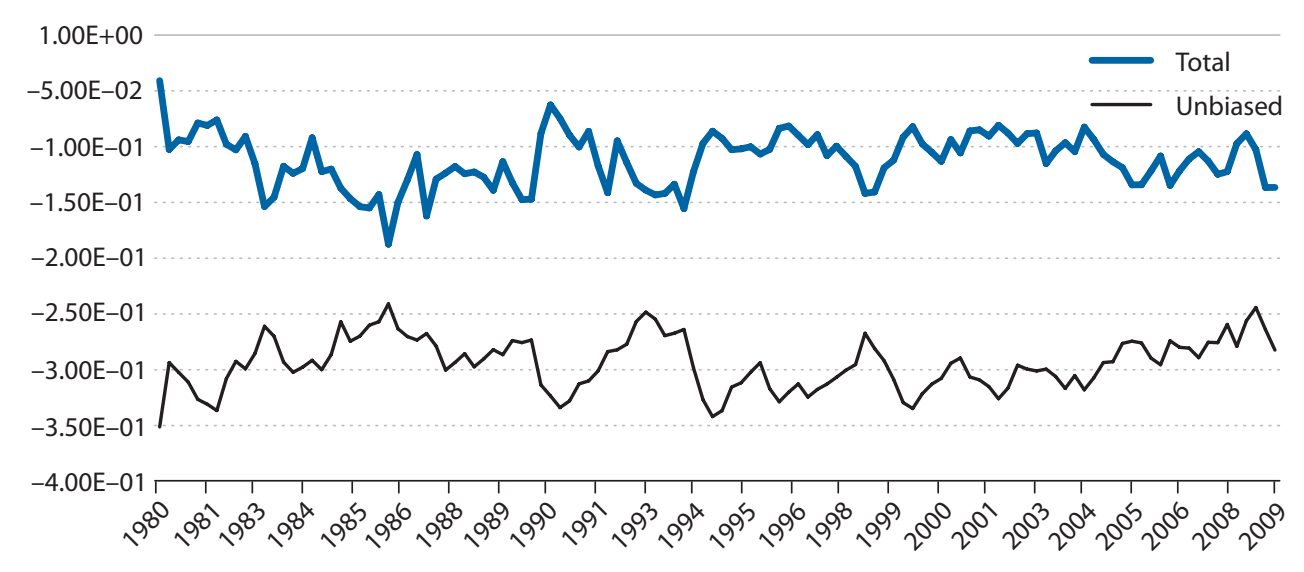




\section{Figure 13}

\section{TVC Estimation of the Interest Rate Effect}

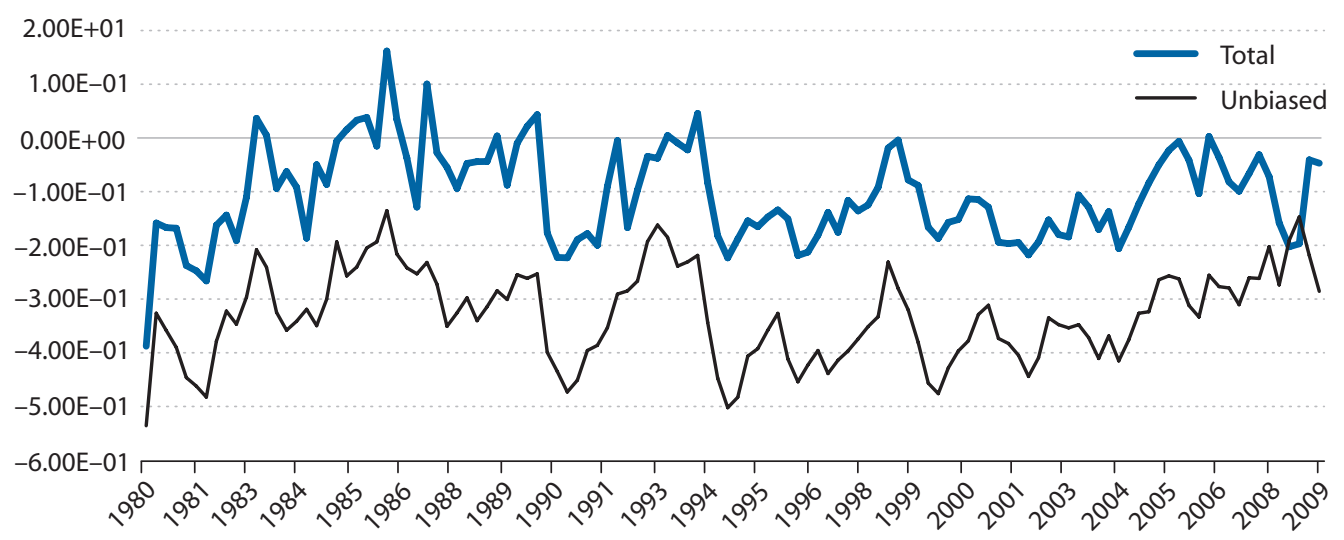

demand for money than changes in housing wealth. Economic agents view given changes in housing wealth as more permanent than the same changes in financial wealth.

- Using both the VEC and the TVC techniques, confidence had a significant impact on money demand; in the case of VEC, it produced cointegration during the extended sample period (i.e., ending in 2009:Q4). Again, however, there were substantial differences in the estimated coefficients. The confidence variable accounted for an increase in money demand during 2007 and 2008 of about 1.3 percent, whereas under the TVC technique, the confidence variable accounted for an increase in money demand of about 10 percent. As shown in Figure 3, real money demand rose at rates in the range of 6 to 8 percent during 2007 and 2008, while the growth rates of income and the two wealth variables were often negative during those years. Consequently, the TVC estimate of the effect of confidence is more helpful than the VEC estimate in explaining why growth in money demand remained at such high levels during those two years. The growth of real money balances declined in 2009 despite rises in the growth rates of real income and financial wealth. However, confidence rose sharply, which acted to reduce money demand. Again, the larger (in absolute value) TVC coefficient on confidence is more consistent with the behavior of real money demand than is the relatively small coefficient on confidence estimated on the basis of the VEC procedure.

- Moreover, there were important differences in implementing the techniques. Achieving cointegration with the VEC technique required us to (i) restrict the income coefficient to unity, (ii) assume that the I(1) confidence variable is exogenous in the cointegrating vector, and (iii) include a split trend and another dummy variable (both beginning in 2002) to capture a change in structure that appears to have occurred three years after the introduction of the euro (in 1999); effectively, the trends capture nonlinearities in the cointegrating relationship. In contrast, with the TVC procedure we were able to estimate coefficients of all the explanatory variables without introducing restrictions and without 


\section{Hall, Swamy, Tavlas}

the need of a split trend to capture nonlinearities; the TVC procedure generalizes cointegration to nonlinear relationships.

\subsection{Parallels with Friedman's Work}

Some clear parallels exist between our work on money demand and the work of Friedman $(1956,1959)$. (i) We previously noted that Friedman (1956) stressed the role of uncertainty, which could lead to prolonged departures from money demand equilibrium. We used a time series on confidence to measure uncertainty and found that it plays an important role in the money demand function. (ii) Cointegration is inherently about long-run relationships. Similarly, Friedman's (1959) empirical work on money demand was inherently long run: The empirical specification did not include a lagged dependent variable to capture adjustment costs (or to correct for serial correlation and/or improve explanatory power), a device that became a standard feature of empirical work beginning in the 1960s. His times series covered a long horizon (i.e., 1869 to 1956) - and the data abstracted from the business cycle - using average values of variables over the cycle. $\underline{.37}$ (iii) Friedman stressed the role of wealth in the money demand function, using permanent income as a proxy for wealth in the absence of the availability of a long-run series on wealth at the time that he wrote. Our results confirm the crucial role of wealth in the money demand function.

\section{CONCLUSIONS}

This paper provides an overview of the ECB's monetary analysis strategy and the pivotal role of monetary factors in the assessment of medium- to longer-term prospects for price stability in the euro area. The ECB's monetary analysis extends beyond simply focusing on developments in M3; it also involves an assessment of various measures of money, as well as credit and financial flows and asset prices. We also demonstrate the many direct connections between the contributions of Milton Friedman and the monetary policy strategy of the ECB.

A salient feature of the ECB's strategy is that it has evolved over the years; the monetary analysis pillar has been - and continues to be-broadened and deepened. Some emphasis was given to a reference value for M3 growth at the inception of the ECB, but currently the M3 reference value plays a relatively minor role within the monetary analysis pillar. One factor accounting for this development was the instability displayed by euro area money demand functions beginning around 2003. Our results, however, indicate that M3 demand, taking into account wealth and confidence, has been stable.

Since the stability of money demand is crucial in assessing the longer-term relationship between money and prices, what are the policy implications of our results? To the extent that deviations in the equilibrium relationship between real money and its determinants are temporary, they can be expected to be self-correcting. In this connection, the international financial crisis of 2007 and 2008 led to a sharp drop in confidence, which contributed to a flight to money. The relatively fast growth rate of euro area real M3 during these two years was not indicative of an overly expansionary monetary policy, but rather of the increase in the demand for money stemming mainly from the precipitous fall in confidence. Nevertheless, confidence tends to be mean reverting; thus, the sharp rise in confidence in 2009 contributed to a decline in real M3 
balances. Our findings, therefore, reinforce the importance of using money demand analysis in a medium- to longer-term context.

\section{NOTES}

1 The ECB's definition of price stability is given in Section 2.

$\underline{2}$ Elements of Friedman's thinking can be found in the monetary policy strategies of other central banks, including those that follow inflation targeting. For an acknowledgment of Friedman's views in influencing the Federal Reserve's policy, see Bernanke (2002).

3 The collaboration with Schwartz resulted in their classic, A Monetary History of the United States, 1867-1960, published in 1963. In his initial correspondence with Schwartz, Friedman estimated that their project would be completed in three years. See Tavlas (2012), on which the discussion in this section draws.

4 The paper was published as part of the collected essays in Friedman (1969).

$\underline{5}$ It should be kept in mind that the Friedman and Schwartz evidence to which Friedman referred in these studies was preliminary. Moreover, during the 1960s Friedman's views on some of the issues discussed below, including the Great Depression, would undergo refinement. The data periods to which Friedman referred in these studies alternated among 1867 to 1954, 1867 to 1957 , and 1870 to 1954 .

6 Subsequently, this measure corresponded to what became known as M2.

$\underline{7}$ Lothian (2009) noted that "By using reference-cycle averages as his basic units of observation, Friedman was able to focus on positions of long-run equilibrium. He, therefore, was able to get around to the problems of monetary endogeneity and the partially related econometric problems inherent in modelling short-run monetary adjustment" (p. 1089). See also Tavlas (1998).

8 See also Friedman (1958, p. 175), which cited evidence on velocity behavior in papers by Cagan (1956) and Selden (1956), both of which were written for the Chicago Workshop in Money and Banking.

9 In a 1973 paper, Friedman argued that "if we knew about autonomous changes in the real demand for money, it would be right to adjust the money supply to them. However, we don't know about them" (Friedman, 1973; quoted in Nelson, 2008, p. 101).

10 Friedman stated that "the evidence for this concept is certainly far from conclusive" (1960, p. 91). In the early 1980 s he switched to M1. Nelson (2007) provides a discussion of the reasons for the switch.

11 The meaning of "medium term" has not been precisely defined by the ECB.

12 The ECB is governed by two main decisionmaking bodies - the Governing Council and the Executive Board. The Governing Council is the main decisionmaking body. It combines the 6-member Executive Board (which includes the president and vice president of the ECB) and the 17 governors of the national central banks of the member states that have adopted the euro. The Governing Council usually meets twice per month in Frankfurt, Germany. At its first meeting each month, the Governing Council assesses economic and monetary developments and makes its monthly monetary policy decision. At its second meeting, the Council discusses issues mainly related to other tasks and responsibilities of the ECB.

13 The HICP is a weighted average of price indexes of the member states of the euro area. Its coverage includes goods and services consumed. The index measures the change in expenditure necessary to maintain unchanged, with respect to a base period, the consumption pattern of households and the composition of the consumer population. See Issing et al. (2001, pp. 51-53).

$\underline{14}$ It is important to note that the ECB's monetary policy strategy reflects a broad range of contributions other than those of Friedman. For a good discussion, see Issing et al. (2001, pp. 32-46).

15 The ECB's monetary policy strategy was, to a substantial extent, based on the earlier strategy of Germany's Bundesbank. Issing and Tristani (2005, p. 50) discussed the influence of Friedman on the Bundesbank's strategy.

${ }^{16}$ For a detailed discussion of the monetary analysis pillar, see Drudi, Moutot, and Vlassopoulos (2010).

17 The sample period used by the ECB to estimate the best-fit criterion typically begins in 1980 . Since euro area-wide data were not available before the start of the euro area on January 1, 1999, data extending back to 1980 were constructed "synthetically."

18 The co-authors of the paper were Fischer, Lenza, Pill, and Reichlin (2007). The paper itself, while acknowledging the breakdown of euro area money demand relationships, stressed the importance of monetary factors and the need to develop new tools to assess the impact of monetary factors on the economy. 


\section{Hall, Swamy, Tavlas}

19 Fischer and Pill wrote: "Money-demand models are the workhorse of [the ECB's] monetary analysis, playing an unglamorous but crucial role in any comprehensive framework for the assessment of monetary conditions" (2010, p. 131).

20 Of the two press reports cited above on the November 2006 ECB conference-those of Handelsblatt and the Financial Times-the latter was more accurate about the implications of the conference for the ECB's monetary analysis pillar. Although researchers found money demand models had broken down, the ECB responded by attempting to improve those models.

21 Friedman (1956) specified a money demand function in which the real quantity of money demand is a function of a vector of returns on alternatives to holding money bonds, equities, physical goods, and human capital.

22 Friedman (1956, pp. 4-9; 1959) considered permanent income to be the relevant measure of wealth in the money demand function. In addition to permanent income, he argued that a variable capturing the ratio of wealth to income should be included in the money demand function. We use a wealth-to-income variable in what follows.

$\underline{23}$ Our specification is identical to that derived by Tobin (1969, p. 20, equation (I.2)), except that Tobin included the ratio of income to wealth rather than the ratio of wealth to income.

24 Suppose that the variables—say, real income, real money balances, and wealth-in a money demand equation are each nonstationary and integrated of order one. The finding of cointegration would mean that the error term in the money demand equation is stationary.

$\underline{25}$ Formal derivations of the ideas discussed in this paper are provided in Swamy and Tavlas $(2005,2007)$. Empirical applications include Hall et al. (2009) and Hall, Swamy, and Tavlas (2012a).

$\underline{26}$ To our knowledge, the first empirical study to include wealth in a money demand specification for the euro area was by Hall et al. (2007). These authors used a single wealth variable. In the absence (at that time) of the availability of a wealth variable for the entire euro area, they constructed a wealth variable on the basis of stock market valuation. They found that the demand for money was stable over the period 1980:Q2-2006:Q4.

27 The time-series properties of all the variables were evaluated using standard unit root tests: the augmented Dickey-Fuller (ADF), Phillips-Perron (PP), and the Kwiatkowski-Phillips-Schmidt-Shin (KPSS) tests. All these tests suggested that real money, real income, the ratio of real financial wealth to real income, the ratio of real housing wealth to real income, and the confidence index were (unit root) nonstationary, while their first differences were stationary. The spread between the interest rate variable and the own rate on $\mathrm{M} 3$ was $\mathrm{I}(0)$. Consequently, the interest rate spread was not included in the cointegrating relationship, although it was included with the VEC as part of the error correction process. Because we focus on the I(1) analysis, real money balances, real income, the ratios of real financial and housing wealth to real income, and the confidence variables were included as I(1) variables in the VAR specification. The interest rate spread was included as an exogenous variable, which was lagged to line up with the cointegrating vectors; since it is stationary, it cannot affect the cointegration among the other variables.

28 This is done by setting up an unrestricted VAR estimation and testing this VAR for misspecification and the cointegrating rank among the variables. To determine the lag length of the VAR model, alternate versions of the system were initially estimated using different lags. An Akaike information criterion, a Schwartz Bayesian criterion, and a Hannan-Quinn criterion were used to determine the lag length. Finally, a VAR model of order two was used in the estimation procedure. For a discussion of these tests, see Maddala and Kim (1998, pp. 45-146).

$\underline{29}$ We do not report these results for the period ending in 2009:Q4 in Table 1. The ADF test statistic is -2.95, compared with a 5 percent critical value of -4.80 . Therefore, we fail to reject the null hypothesis of no cointegration. For the ADF test, we included a split time trend starting in 2002 to proxy the change in behavior that occurred after the introduction of the euro, a dummy that takes a value of unity from 2002 to the end of the sample period, and the opportunity cost of holding M3 minus the own rate on $\mathrm{M} 3$ (which is stationary). These variables were included to make the results comparable with the VEC results reported in what follows.

30 The CUSUM test will not have the standard critical values for a cointegrating regression but the instability is obvious.

31 The ESI was projected backwards to $1980: 01$ as a constant so that we could make use of the full data sample.

$\underline{32}$ In technical terms, uncertainty acts as a fractionally integrated process.

33 The complete results are available from the authors.

34 See Swamy and Tavlas (2001, p. 419).

35 With the exception of the coefficients on the confidence and the opportunity cost variables, the bias-free coefficients are on average very close to the total effect coefficients but, as we will show, much more stable.

$\underline{36}(1 / \mathrm{T}) \sum_{\mathrm{t}=1}^{\mathrm{T}} \sum_{\mathrm{k} \in A_{11 t}} \hat{\pi}_{1 \mathrm{k}} \mathrm{z}_{\mathrm{kt}}=1.17$, where $\hat{\pi}_{1 \mathrm{k}}$ is an iteratively rescaled generalized least squares (IRSGLS) estimator of $\pi_{1 k^{\circ}}$ 
37 Friedman (1959) wrote:"[T]he long time period covered assures that movements in money are dominated by the movements in the permanent component of income" (p. 119). As mentioned above, Friedman (1959) did not include an interest rate in his money demand function. Laidler (1966) performed an exercise similar to Friedman's but included the rate of interest in his regressions. Laidler found that the inclusion of the interest rate improved the predictability of his regressions, confirming the importance of the interest rate as a determinant of the demand for money. Friedman (1966) acknowledged that the interest rate could have an effect on the demand for money.

\section{REFERENCES}

Atkins, Ralph. "Trichet and Bernanke Differ on Strategy." Financial Times, November 10 2006; www.ft.com/intl/cms/s/0/5c5d9f68-70e6-11db-8e0b-0000779e2340.html\#axzz1ns6v6GU7.

Bernanke, Ben. S. "Remarks at the Conference to Honor Milton Friedman." University of Chicago, November 8, 2002 www.federalreserve.gov/BOARDDOCS/SPEECHES/2002/20021108/default.htm.

Beyer, Andreas; Fischer, Bjorn and von Landesberger, Julian. "Money Demand Stability: Implications for the Usefulness of Money in Monetary Policy." Unpublished manuscript, European Central Bank, 2007.

Brainard, William C. and Tobin, James. "Pitfalls in Financial Model-Building." Cowles Foundation Discussion Papers No. 244, 1968, Cowles Foundation for Research in Economics; http://cowles.econ.yale.edu/P/cd/d02a/d0244.pdf.

Cagan, Philip. "The Monetary Dynamics of Hyperinflation," in Milton Friedman, ed., Studies in the Quantity Theory of Money. Chicago: University of Chicago Press, 1956, pp. 25-117.

Calza, Allesandro; Gerdesmeier Dieter and Levy, Joaquim. "Euro-Area Money Demand: Measuring the Opportunity Cost Appropriately." IMF Working Paper No. 01/179, International Monetary Fund, November 2001; www.imf.org/external/pubs/ft/wp/2001/wp01179.pdf.

Carboni, Giacomo; Hofmann, Baris and Zampolli, Fabrizio. "The Role of Money in the Economy and in Central Bank Policies," in Lucas Papademos and Jürgen Stark, eds., Enhancing Monetary Analysis. Chap. 1. Frankfurt: European Central Bank, 2010, pp. 17-71.

Cuthbertson, Keith; Hall, Stephen G. and Taylor, Mark P. Applied Econometric Techniques. Ann Arbor, MI: Phillip Allen, 1991.

Davidson, James and Hall, Stephen G. “Cointegration in Recursive Systems.” Economic Journal, March 1991, 101(405), pp. $239-51$.

Drudi, Francesco; Moutot, Philippe and Vlassopoulos Thomas. "Monetary Analysis in the ECB's Monetary Policy Process," in Lucas Papademos and Jürgen Stark, eds., Enhancing Monetary Analysis. Chap. 2. Frankfurt: European Central Bank, 2010, pp. 73-127.

European Central Bank. The Monetary Policy of the ECB. Frankfurt: European Central Bank. 1999.

European Central Bank. The Monetary Policy of the ECB. Frankfurt: European Central Bank, 2001.

European Central Bank. Press Release. "The ECB's Monetary Policy Strategy." May 8, 2003; www.ecb.int/press/pr/date/2003/html/pr030508_2.en.html.

European Central Bank. The Monetary Policy of the ECB. Frankfurt: European Central Bank, 2011; www.ecb.int/pub/pdf/other/monetarypolicy2011en.pdf.

Fischer, Bjorn; Lenza, Michele; Pill, Huw and Reichlin, Lucrezia. "Money and Monetary Policy: The ECB Experience 1999-2006." Unpublished manuscript, European Central Bank, November 6, 2007; www.ecb.int/events/pdf/conferences/cbc4/ReichlinPillLenzaFisher.pdf.

Fischer, Bjorn and Pill, Huw. "Improving Models of Euro Area Money Demand," in Lucas Papademos and Jürgen Stark, eds., Enhancing Monetary Analysis. Chap. 3. Frankfurt: European Central Bank, 2010, pp.131-55.

Friedman, Milton. "The Quantity Theory of Money—A Restatement," in M. Friedman, ed., Studies in the Quantity Theory of Money. Chicago: University of Chicago Press, 1956, pp. 3-21.

Friedman, Milton. "The Supply of Money and Changes in Prices and Output," in 85th Congress, 2nd Session, Joint Economic Committee: The Relationship of Prices to Economic Stability and Growth: Compendium of Papers Submitted by Panelists Appearing before the Joint Economic Committee. Hearings before the Joint Economic Committee, May 12-22, 1958. Washington, DC: U.S. Government Printing Office, 1958. Reprinted in Friedman, 1969, pp. 241-56.

Friedman, Milton. "The Demand for Money: Some Theoretical and Empirical Results." Journal of Political Economy, August 1959, 67(4), pp. 327-51. Reprinted in Friedman, 1969. 


\section{Hall, Swamy, Tavlas}

Friedman, Milton. A Program for Monetary Stability. New York: Fordham University Press, 1960.

Friedman, Milton. "Interest Rates and the Demand for Money." Journal of Law and Economics, October 1966, 9, pp. 71-85.

Friedman, Milton. “The Role of Monetary Policy." American Economic Review, March 1968, 58(1), pp. 1-17.

Friedman, Milton. The Optimum Quantity of Money. Chicago: University of Chicago Press, 1969.

Friedman, Milton. Money and Economic Development: The Horowitz Lectures of 1972. New York: Praeger, 1973.

Friedman, Milton and Schwartz, Anna. A Monetary History of the United States. Princeton, NJ: Princeton University Press, 1963.

Granger, Clive W.J. “Non-Linear Models: Where Do We Go Next-Time Varying Parameter Models?” Studies in Nonlinear Dynamics and Econometrics, 2008, 12(3), pp. 1-9.

Greene, William, H. Econometric Analysis. Sixth Edition. Upper Saddle River, NJ: Pearson Education, 2008.

Hall, Stephen; Hondroyiannis, George; Swamy, P.A.V.B. and Tavlas, George S. "A Portfolio Balance Approach to Euro-Area Money Demand in a Time-Varying Environment." Bank of Greece Working Paper No. 61, October 2007; www.bankofgreece.gr/BogEkdoseis/Paper200761.pdf.

Hall, Stephen, G.; Hondroyiannis, George; Swamy, P.A.V.B. and Tavlas, George S. “The New Keynesian Philips Curve and Lagged Inflation: A Case of Spurious Correlation?" Southern Economic Journal, October 2009, 76(2), pp. 467-81.

Hall, Stephen G.; Swamy, P.A.V.B. and Tavlas, George S. "Generalised Cointegration: A New Concept with an Application to Health Expenditure and Health Outcomes." Empirical Economics, April 2012a, 42(2), pp. 603-18.

Hall, Stephen G.; Swamy, P.A.V.B. and Tavlas, George S. "Generalized Cointegration: A Nonlinear Concept." Unpublished manuscript, Bank of Greece, 2012b.

Handelsblatt. "The Role of Money." November 10, 2006; www.handelsblatt.com/politik/konjunktur/shadow-council/links-to-recent-research-papers/2618860.html.

Issing, Otmar. The Birth of the Euro. Cambridge, UK: Cambridge University Press, 2008.

Issing, Otmar; Gaspar, Vitor; Angeloni, Ignazio and Tristani, Oreste. Monetary Policy in the Euro Area. Cambridge, UK: Cambridge University Press, 2001.

Issing, Otmar; Gaspar, Vitor and Vestin, David. "Imperfect Knowledge, Leaning and Conservatism," in O. Issing, ed., Imperfect Knowledge and Monetary Policy. Cambridge, UK: Cambridge University Press, 2005, pp 77-116.

Issing, Otmar and Tristani, Oreste. "Monetary Policy in Uncharted Territory," in O. Issing, ed., Imperfect Knowledge and Monetary Policy. Cambridge, UK, Cambridge University Press, 2005, pp. 12-76.

Johansen, Soren. "Identifying Restrictions of Linear Equations with Applications to Simultaneous Equations and Cointegration." Journal of Econometrics, September 1995, 69, pp. 111-32.

Laidler, David. "The Rate of Interest and the Demand for Money-Some Empirical Evidence." Journal of Political Economy, December 1966, 74, pp. 545-55.

Lothian, James R. "Milton Friedman's Monetary Economics and the Quantity-Theory Tradition." Journal of International Money and Finance, November 2009, 28(7), pp. 1086-96.

Maddala, G.S. and Kim, In-Moo. Unit Roots, Cointegration, and Structural Change. New York: Cambridge University Press, 1998.

Nelson, Edward. "Milton Friedman and U.S. Monetary History: 1961-2006." Federal Reserve Bank of St Louis Review, May/June 2007, 89(3), pp. 153-82; http://research.stlouisfed.org/publications/review/08/03/Nelson.pdf.

Nelson, Edward. "Friedman and Taylor on Monetary Policy Rules: A Comparison." Federal Reserve Bank of St. Louis Review, March/April 2008, 90(2), pp. 95-116; http://research.stlouisfed.org/publications/review/07/05/Nelson.pdf.

Papademos, Lucas and Stark, Jürgen. “Foreword," in Lucas Papademos and Jürgen Stark, eds., Enhancing Monetary Analysis. Frankfurt: European Central Bank, 2010, pp. 8-13.

Phelps, Edmund. "Money and Wage Dynamics and Labor Market Equilibrium." Journal of Political Economy, 1968, 76, pp. 678-721.

Selden, Richard T. "Monetary Velocity in the United States," in Milton Friedman, ed., Studies in the Quantity Theory of Money. Chicago: University of Chicago Press, 1956, pp. 179-257.

Swamy, P.A.V.B. and Mehta, J.S. "Bayesian and Non-Bayesian Analysis of Switching Regressions and of Random Coefficient Regression Models." Journal of the American Statistical Association, September 1975, 70(351), pp. 593-602. 
Hall, Swamy, Tavlas

Swamy, P.A.V.B. and Tavlas, George S. "Random Coefficient Models," in B. Baltagi, ed., A Companion to Theoretical Econometrics. Malden, MA: Blackwell, 2001, pp. 410-28.

Swamy, P.A.V.B. and Tavlas, George S. "Theoretical Conditions Under Which Monetary Policies Are Effective and Practical Obstacles to Their Verification." Economic Theory, June 2005, 25(4), pp. 999-1006.

Swamy, P.A.V.B. and Tavlas, George S. “The New Keynesian Philips Curve and Inflation Expectations: Re-Specification and Interpretation." Economic Theory, May 2007, 31(2), pp. 293-306.

Swamy, P.A.V.B.; Tavlas, George S.; Hall, Stephen G. and Hondroyiannis, George. "Estimation of Parameters in the Presence of Model Misspecification and Measurement Error." Studies in Nonlinear Dynamics and Econometrics, 2010, 14(3), pp. 1-33.

Tavlas, George S. "Was the Monetarist Tradition Invented?" Journal of Economic Perspectives, Fall 1998, 12(4) pp. 211-22.

Tavlas, George S. "In Old Chicago: Simons, Friedman and Monetary-Policy Rules.” Unpublished manuscript, Bank of Greece, 2012.

Tobin, James. "A General Equilibrium Approach to Monetary Theory." Journal of Money, Credit, and Banking, February 1969, 1, pp. 15-29.

Trichet, Jean-Claude. "Money's Vital Role in Monetary Policy." Financial Times, November 7, 2006; www.ft.com/intl/cms/s/1/99fb6c6e-6f57-11db-ab7b-0000779e2340.html\#axzz1plpAtn74. 


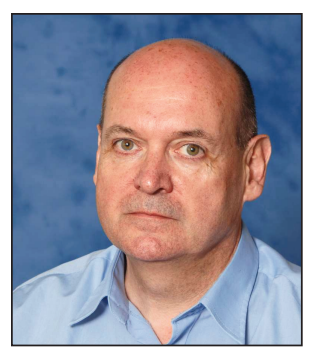

\section{Stephen G. Hall}

Professor of economics, Leicester University, visiting professor at Pretoria University, and consultant to the Bank of Greece

http://www.le.ac.uk/ec/staff/sh222.html

\section{Research Focus}

Stephen Hall's main areas of research are macroeconomics and econometrics, with a special emphasis on empirical macroeconomic models.

\section{P.A.V.B. Swamy}

Former senior economist in the Division of Research and Statistics,

Board of Governors of the Federal Reserve System

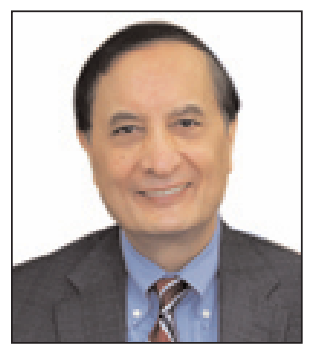

\section{George S. Tavlas}

Director general of the Bank of Greece and the alternate to the Bank of Greece's governor on the Governing Council of the European Central Bank 